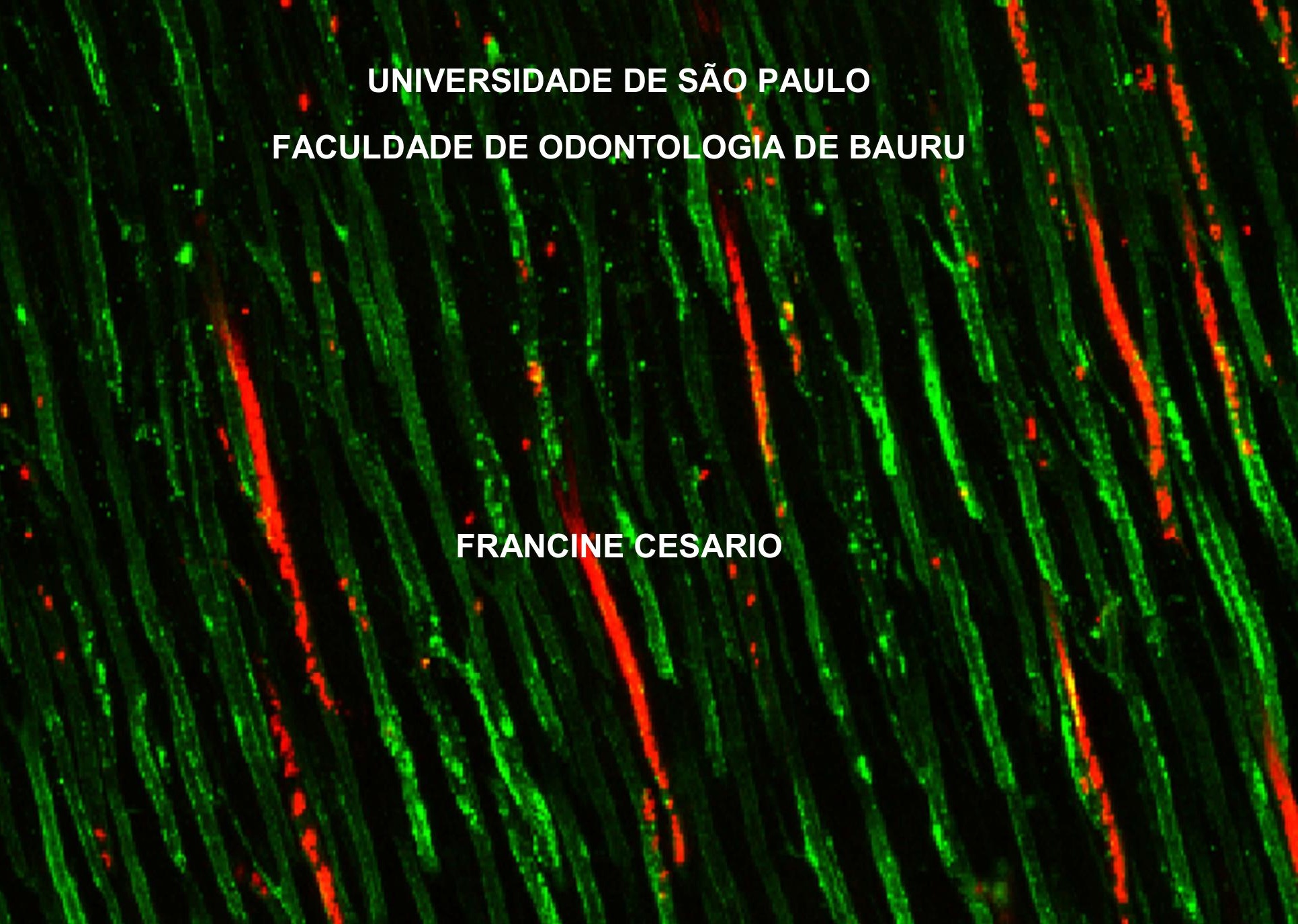

Desinfecção intratubular dentinăria promovida por soluções irrigadoràs com variação de $\mathrm{pH}$ e agitą̧ẳo ultrassônica 

FRANCINE CESARIO

\title{
Desinfecção intratubular dentinária promovida por soluções irrigadoras com variação de pH e agitação ultrassônica
}

\begin{abstract}
Dissertação constituída por artigo apresentada a Faculdade de Odontologia de Bauru da Universidade de São Paulo para obtenção do título de Mestre em Ciências no Programa de Ciências Odontológicas Aplicadas, na área de concentração Endodontia.
\end{abstract}

Orientador: Prof. Dr ${ }^{\mathrm{a}}$ Flaviana Bombarda de Andrade

\section{Versão corrigida}

\section{BAURU}




\begin{tabular}{|c|}
\hline Cesario, Francine \\
Desinfecção intratubular dentinária promovida por \\
soluções irrigadoras com variação de pH e agitação \\
ultrassônica / Francine Cesário. - Bauru, 2016. \\
60 p. : il. ; $31 \mathrm{~cm}$. \\
Dissertação Mestrado - Faculdade de Odontologia \\
de Bauru. Universidade de São Paulo \\
Orientador: Prof. Dr ${ }^{\text {a }}$. Flaviana Bombarda de \\
Andrade
\end{tabular}

Nota: a versão original desta dissertação encontra-se disponível no serviço de biblioteca da faculdade de Odontologia de Bauru- FOB/USP.

Autorizo, exclusivamente para fins acadêmicos e científicos, a reprodução total ou parcial desta dissertação/tese, por processos fotocopiadores e outros meios eletrônicos.

Assinatura: 


\section{$\mathcal{D E D I C A \mathcal { T O } R I \mathcal { A }}$}

À Deus, pela minha família e amígos, por guiar meus passos, mostrando a luz nos momentos de dífículdade e pela força para superar os obstáculos. "Intregue seu caminho ao senhor, nele confie e ele agirá.Salmo 37 (36),5".

Aos meus país Izilda e Edvaldo, uma vida inteira seria pouco para agradecer o que fazem por mim, vocês são minha base, meu porto seguro.

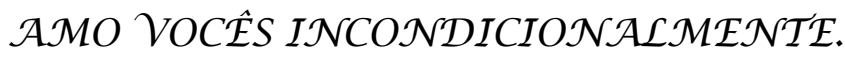

À minha $\mathcal{M a ̃ e}$ Izilda, a pessoa que mais admiro no mundo. Exemplo de dedicação, coragem, força e amor. Agradeço por todas as vezes em que sem hesitar sacrificou os seus sonhos para que eu possa realizar os meus, por estar ao meu lado e sempre me apoiar em toda e qualquer situação. Você é meu exemplo de vida, de mulher, mãe, esposa! $\mathcal{E} U \mathcal{T} \mathcal{E} \mathcal{A} \mathcal{M} O$.

Ao meu irmão, Fábio e minha cunhada Danielle, por estarem ao meu lado me apoiando e me socorrendo sempre que preciso. Obrigada por fazerem parte da minha vida.

Ao meu namorado, Ricardo, por todos esses anos ao meu lado compartilhando das minhas conquistas como se fossem suas. Obrigada por me apoiar e me incentivar a buscar sempre o methor e entender minhas ausências. $\mathcal{T} \mathcal{E} \mathcal{A M O}$ 



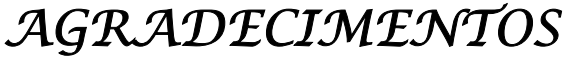

À minha orientadora Professora $\mathcal{D} r^{a}$. Flaviana Bombarda de Andrade pela orientação, disponibilidade, paciêncía, por todos os conselhos e palavras de incentivo durante a execução da pesquisa e também por depositar sua confiança em mim. Obrigada pela amizade e todos os ensinamentos ao longo desses anos. Quero que saiba que a admiro muito. Obrigada.

Ao Professor Dr. Rodrigo Vivan, meu maior exemplo durante a graduação, por seu profissionalismo, empenho e dedicação à profissão e aos alunos. Agradeço por ter me ensinado os prímeiros passos na endodontía e na ciência através da iniciação científíca. Fíco muito feliz em ter reencontrado e poder ter novamente como professor nesta jornada. Minha gratídão e reconhecimento. Obrigada pela amizade.

Aos Professores Marco Antonio Hungaro Duarte, Ivaldo Gomes de Moraes, Clóvis Monteiro Bramante, Roberto Brandão García e Norbertí Bernardineli da disciplina de endodontia da FOB/USP por todo carinho, atenção, paciência e por todos os valiosos ensinamentos transmitidos durante a nossa convivêncía. Tenho uma imensa admiração, carinho e respeito.

Aos funcionários do Departamento de Endodontía Suely, Andressa e Edimauro pelo carinho e convivêncía agradável durante esses anos.

À especialista em laboratório do centro integrado em pesquísa da FOBUSP, Márcía Sirlene Zardin Graeff, pela ajuda no Microscópio Confocal de Varredura a Laser. Obrigada pela paciêncía, em sempre estar disposta em me atender. Você foi fundamental para a realização dente trabalho. 

Ao técnico de laboratório Marcelo Miranda Ríbeiro Lopes que sempre estava pronto para ajudar e ensinar a manusear os equipamentos do Caboratório.

À técnica do laboratório de bioquímica da FOB Thelma Lopes Silva, pela paciêncía, pelas explicações e apoío para o preparo das soluções irrigadoras. Você também foi essencial para realização deste trabalho.

Aos meus amigos de turma Bruno Piazza, Denise Ferraciolli Oda, Jussaro Alves Duque e Rafaela Fernandes Zancan, por todos os bons momentos, experiência e conhecimentos que dividimos.

Às minhas colegas Raquel Zanin Midena e Layla Vasconcelos que por muitas vezes me ajudaram nos momentos de dificuldade e com paciência elucidaram minhas dúvídas relacionadas à pesquísa.

Aos meus amigos do doutorado Bruno Martini Guimarães e Murilo Priori Alcalde, por sempre estarem ao meu lado e se colocando à disposição para ajudar, pelos conselhos, conhecimento e experiências que dividiram comigo.

Aos meus colegas da pós - graduação, Pablo Andrés Amoroso Silva, Marcela Milanezi de Almeida, Amanda Garcia Alves Maliza, Lyz Cristina Furquim Canali, Talita Tartari, Fernanda Fernandes, Clarissa Teles, Thais Cristina Pereira, Erícson Janolio de Camargo, Paloma Minotti Bonfante, Samuel Lucas Fernandes, Sávio Brandeleiro, Bruno Cavalini Cavenago e Lincoln Fruchi pela convivência agradável e trocas de experiências. 



\section{Agradecimentos institucionaís}

À faculdade de Odontologia de Bauru, Universidade de São Paulo, na pessoa do diretor, Professora Dra. María Aparecida Moreira Machado.

À comissão de pós-graduação na pessoa do Professor Dr. Guitherme dos Reis Pereira Janson.

Ao coordenador do programa da pós-graduação em Endodontia Professor Dr. Marco Antonio Hungaro Duarte.

Aos funcionários da pós-graduação Maria Margareth Pereira Morzakel, Ana Letícia Palombo Momesso, Fatima Cassador Carvalho, Elaine Falcão Tuler Xavier e Leila Regina da Sílva Yerga Xavier por sempre estarem a disposição em ajudar e serem atenciosas, muito obrigada.

Ao Conselho $\mathcal{N a c i o n a l}$ de Desenvolvimento Científico e Tecnológico - CNNPq pelo financiamento deste projeto.

Ao Centro Integrado de Pesquisas da Faculdade de Odontología de BauruUSP, na pessoa do Professor Dr. Rodrigo Cardoso de Oliveira. 

"Há uma força motriz mais poderosa que o vapor, a eletricidade e a energia atômica: à vontade". 



\section{RESUMO}

Este estudo objetiva analisar a influência da variação de pH de soluções irrigadoras e agitação ultrassônica na descontaminação intratubular de dentes bovinos contaminados por Enterococcus faecalis. Noventa e seis dentes incisivos bovinos foram esterilizados e contaminados com Enterococcus faecalis seguindo um protocolo padronizado por um período de cinco dias. Os espécimes foram submetidos à irrigação com cinco $\mathrm{mL}$ por cinco minutos com hipoclorito de sódio (NaOCl) 1\% pH5 sem agitação ultrassônica (G1); NaOCl a 1\% pH5 com agitação ultrassônica (G2); $\mathrm{NaOCl}$ 2,5\% pH5 sem agitação ultrassônica (G3); $\mathrm{NaOCl}$ a 2,5\% pH5 com agitação ultrassônica (G4); NaOCl a 1\% pH10 sem agitação ultrassônica (G5); $\mathrm{NaOCl}$ a 1\% pH10 com agitação ultrassônica (G6); NaOCl a 2,5\% pH10 sem agitação ultrassônica (G7); $\mathrm{NaOCl}$ a 2,5\% pH10 com agitação ultrassônica (G8); clorexidina (CLX) a 2\% sem agitação ultrassônica (G9); CLX com agitação ultrassônica (G10), constituindo dez grupos-teste, além dos controles positivo e negativo. Os espécimes foram analisados através de imagens no software Bioimagel adquiridas em microscópio confocal de varredura a laser (MCVL), para quantificar as bactérias viáveis após a irrigação. Foram realizados testes de normalidade Shapiro Wilk e D’ Agostino e Pearson seguido dos testes comparativos de Kruskal-Wallis e Dunn $(p<0.05)$. Todos os grupos diminuíram a quantidade de células bacterianas viáveis em relação ao controle. Os grupos de $\mathrm{NaOCl}$ com $\mathrm{pH} 5$ associados a agitação ultrassônica ou não, juntamente com o grupo CLX com ultrassom reduziram maior quantidade de células viáveis quando comparados aos outros grupos. Nenhum grupo eliminou totalmente Enterococcus faecalis dos canais. Desta forma, a solução de hipoclorito de sódio acidificada provocou uma diminuição significante do número de bactérias. $\mathrm{O}$ uso do ultrassom promoveu maior efetividade antimicrobiana no irrigante clorexidina.

Palavras-chave: Enterococcus faecalis. Hipoclorito de sódio. Acidificação. Clorexidina. Terapia por ultrassom 



\section{ABSTRACT \\ Dentinal intratubular disinfection promoted by irrigating solutions with $\mathrm{pH}$ variations and ultrassonic agitation}

The aim of this study was to analyze the influence of $\mathrm{pH}$ variation of irrigating solutions and ultrasonic agitation in intratubular cleanliness in bovine teeth contaminated by Enterococcus faecalis. Ninety-six bovine incisor teeth were sterilized and infected with Enterococcus faecalis by a standardized protocol for a period of five days. The specimens were subjected to an irrigation protocol with $5 \mathrm{~mL}$ of sodium hypochlorite $(\mathrm{NaOCl}) 1 \%$ for five minutes with $\mathrm{pH} 5$ without ultrasonic agitation (G1); $\mathrm{NaOCl} 1 \%, \mathrm{pH} 5$ with ultrasonic agitation (G2); $\mathrm{NaOCl} 2.5 \%, \mathrm{pH} 5$ without ultrasonic agitation (G3); $\mathrm{NaOCl} 2.5 \%, \mathrm{pH} 5$ with ultrasonic agitation (G4); $\mathrm{NaOCl} 1 \%, \mathrm{pH} 10$ without ultrasonic agitation (G5); $\mathrm{NaOCl} 1 \%, \mathrm{pH} 10$ with ultrasonic agitation (G6); $\mathrm{NaOCl} 2.5 \%, \mathrm{pH} 10$ without ultrasonic agitation (G7); $\mathrm{NaOCl} 2.5 \%$, pH10 with ultrasonic agitation (G8); Chlorhexidine (CLX) 2\% without ultrasonic agitation (G9); CLX with ultrasonic agitation (G10), composing ten test groups, besides to positive and negative controls. The specimens were analyzed using images with Bioimagel software acquired by confocal laser scanning microscope (CLSM) to quantify viable bacteria after irrigation. The Shapiro Wilk and D' Agostino Pearson normality tests was performed, followed by Kruskal-Wallis and Dunn comparative tests $(p<0.05)$. All groups decreased the number of viable bacterial cells compared to controls. The $\mathrm{NaOCl}$ group $\mathrm{pH} 5$ associated or not with ultrasonic agitation and CLX with ultrasonic agitation group reduced the amount of viable cells compared to the other groups. No one group eliminated completely Enterococcus faecalis from root canals. Therefore, the acidified $\mathrm{NaOCl}$ solution caused a significant decrease in the number of bacteria. The use of ultrasound promoted greater antimicrobial effectiveness associated to chlorhexidine.

Key words: Enterococcus faecalis; Sodium hypochlorite; Acidification; Chlorhexidine; Ultrasonic Therapy 



\section{SUMÁRIO}

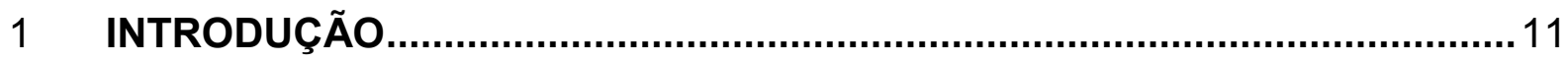

2 ARTIGO

2.1 Artigo 1 - Desinfecção intratubular dentinária promovida por soluções irrigadoras com variação de pH e agitação ultrassônica.

$3 \quad$ DISCUSSÃO

4 CONCLUSÃO

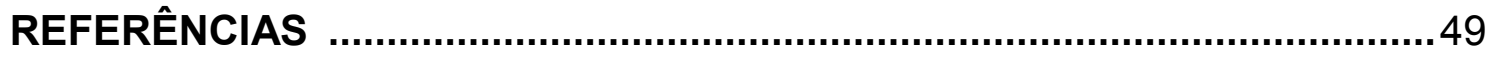

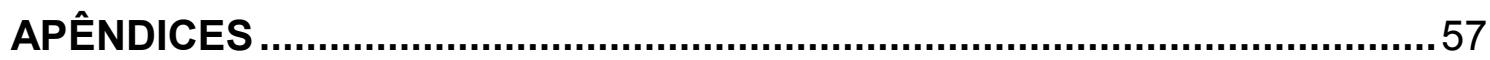





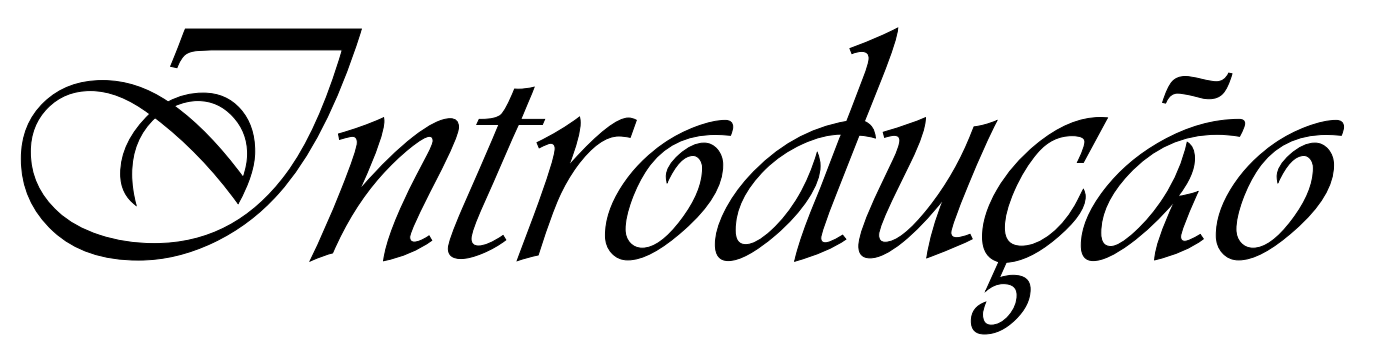





\section{INTRODUÇÃO}

Os micro-organismos e seus produtos são 0 principal fator de desenvolvimento de doenças da polpa e periápice (SIQUEIRA et al., 2001). O tratamento endodôntico tem como principal objetivo a diminuição e controle desses micro-organismos (RICUCCl et al.,2009).

A anatomia interna dos dentes é um fator que contribui para o abrigo de micro-organismos devido a sua complexidade como a presença de istmos, canais laterias e deltas apicais (VERA et al., 2012).

Enterococcus faecalis é uma bactéria anaeróbia facultativa, Gram - positiva e fermentativa. Suas células são ovóides, com tamanho de 0,5 a $1 \mu \mathrm{m}$ de diâmetro. Organizam-se individualmente, em pares ou cadeias curtas e está frequentemente relacionada a infecções persistentes (PINHEIRO et al. 2003). Tem capacidade de invadir túbulos dentinários e permanecer viável mesmo em pH alcalino (LOVE, 2001; NAKAJO et al.,2006; DEL CARPIO PEROCHENA et al, 2015). Possui fatores de virulência relacionados à agregação e à adesão ao substrato dentinário (DELBONI, 2009, PINHEIRO et al. 2013), ela consegue ficar cultivável, mas não viável.

A fase de irrigação exerce o papel fundamental na movimentação ou solubilização do tecido pulpar, remoção dos micro-organismos, seus produtos e subprodutos, partículas teciduais ou estranhas ao canal e toxinas, permitindo a ação da medicação intracanal e consequentemente, facilitar o reparo (VAN DER SLUIS et al., 2010).

O hipoclorito de sódio $(\mathrm{NaOCl})$ tem sido largamente utilizado como auxiliar químico na desinfecção dos canais radiculares. É uma solução alcalina, que possui um duplo modo de ação: habilidade de dissolução de tecidos vivos ou necróticos pela formação de hidróxido de sódio, além da propriedade antimicrobiana devido à formação de compostos contendo cloro ativo, como o ácido hipocloroso ( $\mathrm{HOCl})$ e o íon hipoclorito (OCl-) (LOPES; SIQUEIRA JR., 2010). A solução de $\mathrm{NaOCl}$ com pH baixo favorece o aumento de $\mathrm{HOCl}$, o qual possui maior potencial desinfetante que $\mathrm{O}$ íon hipoclorito (BREMER; MONK; BUTLER, 2002). 
O Gluconato de clorexidina ( $C L X)$ é um agente antimicrobiano de amplo espectro sendo indicado como medicamento no tratamento endodôntico (CARBAJAL MEJIA, 2013). Quando utilizado como irrigante tem uma eficácia antibacteriana comparável ao Hipoclorito de sódio (SIQUEIRA et al., 1998). Possui efeito residual por longo tempo na dentina radicular (WHITE; HAYS; JANER; 1997). Não possui algumas das características indesejáveis do hipoclorito de sódio como instabilidade e irritação dos tecidos periapicais (BRAMANTE et al., 2015). No entanto, sua desvantagem em relação ao $\mathrm{NaOCl}$ é que a $\mathrm{CLX}$ não apresenta capacidade de dissolução tecidual (NAENNI; THOMA; ZEHNDER, 2004).

A anatomia do sistema de canais radiculares possui uma grande complexidade, apresentando áreas de anfractuosidades, istmos, canais laterais e delta apicais, favorecendo dessa forma a permanência de micro-organismos (VERA et al., 2012; Ricucci e Siqueira, 2010) e tecidos, bem como o acúmulo de debris dentinários provenientes da instrumentação (PAQUE et al., 2009). Vários estudos demonstraram que esse acúmulo de debris tem um impacto negativo prejudicando a correta sanificação e a capacidade de selamento da obturação do sistema de canais radiculares (HAAPASALO et al., 2007; DE-DEUS et al., 2008; PAQUE et al., 2009).

O sucesso do processo de irrigação depende tanto da ação física dos irrigantes para a remoção de restos orgânicos, debris dentinários e microorganismos quanto da sua capacidade química de dissolução tecidual (ABOURASS; PICCININO, 1982; LEE; WU; WESSELINK, 2004), porém a irrigação convencional não é capaz de atingir todas as paredes do canal radicular, deixando cerca de $20 \%$ de área não atingida (VERSIANI et al., 2014). A irrigação ultrassônica passiva (PUI) tem sido sugerida a fim de potencializar a capacidade de limpeza do canal radicular (ALVES et al.,2011).

Este método de irrigação (PUI) é classificado como a forma mais eficiente de remover debris do sistema de canais radiculares, devido aos efeitos biológicos da agitação ultrassônica como a microvaporização acústica, forças de radiação, efeito reflexivo, forças de radiação e o principal que é a formação da cavitação transitória que leva a formação de bolhas no líquido irrigante. Essas bolhas se rompem liberando energia e formando ondas que são chamadas de "shock wave"ou ondas de impacto. Essas ondas fazem com que o líquido seja jogado para áreas onde o 
instrumento endodôntico não tocou, como regiões de istmo (ALVES et al., 2011; RODIG et al., 2010) canais laterais, achatamentos e atingindo em profundidade os túbulos dentinários, reduzindo a população microbiana do sistema de canais, que apresentam áreas de difícil acesso devido a sua complexidade anatômica (KLYN; KIRKPATRICK; RUTLEDGE, 2010).

A associação da PUI ao hipoclorito de sódio vem mostrando um efeito maior na remoção de restos pulpares, bactérias e debris do canal radicular (HARRISON et al.,2010). No entanto Enterococcus faecalis é uma bactéria mais resistente e difícil de matar, permanecendo viável dentro do sistema de canais radiculares (LOVE et al.,2001).

A associação do hipoclorito de sódio com a clorexidina tem sido proposta como irrigante final para potencializar a ação de limpeza do sistema de canais radiculares (ZENDER, 2006). Porém a mistura dos dois irrigantes proporciona uma reação química e como consequência a formação de um precipitado de cor marrom. Esse precipitado é de difícil remoção do canal, pode causar descoloração dentária, bloquear canais laterais e prejudicar o selamento da obturação além de conter uma substância tóxica, a para-cloroanilina. Estudos mostram que essa substância tem potencial carcinogênico (CHHABRA et al., 1991) e pode causar metahemoglobinemia.

$\mathrm{O}$ hipoclorito de sódio em $\mathrm{pH}$ ácido tem mostrado um efeito antibacteriano maior do que em pH alcalino (MERCADE et al., 2009; GUERREIRO TANOMARU et al., 2011; DEL CARPIO PEROCHENA et al., 2015). O trabalho de Maliza em 2013 mostrou que soluções de $\mathrm{NaOCl}$ acidificadas mesmo em menores concentrações proprocionaram maior morte microbiana intradentinária, igualando seu efeito às soluções mais concentradas. Como soluções acidificadas possuem menor capacidade de dissolução tecidual (DEL CARPIO PEROCHENA et al., 2015), recomendou-se o uso das soluções acidificadas como irrigante final (MALIZA et al., 2013). Desta forma, não seria necessária a utilização da clorexidina após o uso de $\mathrm{NaOCl}$ evitando a possível formação deste precipitado insolúvel.

Baseado nestas informações, justifica-se avaliar por meio de microscopia confocal de varredura a laser (MCVL), a influência da agitação ultrassônica na 
descontaminação intratubular dentinária de dentes bovinos por soluções de clorexidina a $2 \%$ e de hipoclorito de sódio a 1 e $2,5 \%$ com variações de $\mathrm{pH}$. 


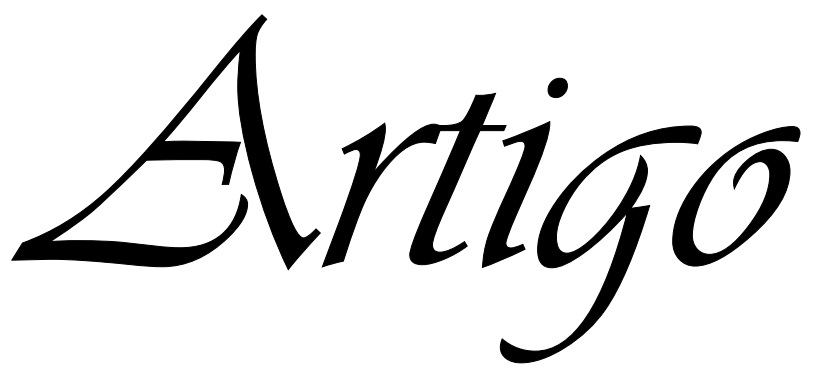





\section{ARTIGO}

O artigo apresentado nesta dissertação foi escrito de acordo com as instruções e orientações para a submissão de artigos apresentados no Dental Press Endodontics.

\subsection{Artigo 1}

Título: Desinfecção intratubular dentinária promovida por soluções irrigadoras com variação de pH e agitação ultrassônica. 


\section{Resumo}

Objetivo: analisar a influência da variação de $\mathrm{pH}$ de soluções irrigadoras e agitação ultrassônica na descontaminação intratubular de dentes bovinos contaminados por Enterococcus faecalis. Material e Métodos: Noventa e seis dentes incisivos bovinos foram esterilizados e contaminados com Enterococcus faecalis seguindo um protocolo padronizado por um período de cinco dias. Os espécimes foram submetidos à irrigação com cinco $\mathrm{mL}$ por cinco minutos com hipoclorito de sódio (NaOCl) 1\% pH5 sem agitação ultrassônica (G1); NaOCl a 1\% pH5 com agitação ultrassônica (G2); $\mathrm{NaOCl}$ 2,5\% pH5 sem agitação ultrassônica (G3); $\mathrm{NaOCl}$ a 2,5\% pH5 com agitação ultrassônica (G4); $\mathrm{NaOCl}$ a 1\% pH10 sem agitação ultrassônica (G5); $\mathrm{NaOCl}$ a $1 \%$ pH10 com agitação ultrassônica (G6); NaOCl a 2,5\% pH10 sem agitação ultrassônica (G7); $\mathrm{NaOCl}$ a 2,5\% pH10 com agitação ultrassônica (G8); clorexidina (CLX) a 2\% sem agitação ultrassônica (G9); CLX com agitação ultrassônica (G10), constituindo dez grupos-teste, além dos controles positivo e negativo. Os espécimes foram analisados através de imagens no software Bioimagel adquiridas em microscópio confocal de varredura a laser (MCVL), para quantificar as bactérias viáveis após a irrigação. Foram realizados testes de normalidade Shapiro Wilk e D`Agostino e Pearson seguido dos testes comparativos de Kruskal-Wallis e Dunn $(p<0.05)$.Resultados: Todos os grupos diminuíram a quantidade de células bacterianas viáveis em relação ao controle. Os grupos de $\mathrm{NaOCl}$ com pH5 associados a agitação ultrassônica ou não, juntamente com o grupo CLX com ultrassom reduziram maior quantidade de células viáveis quando comparados aos outros grupos. Nenhum grupo eliminou totalmente Enterococcus faecalis dos canais. Conclusão: A solução de hipoclorito de sódio acidificada provocou uma diminuição significante do número de bactérias. O uso do ultrassom promoveu maior efetividade antimicrobiana no irrigante clorexidina.

Palavras-chave: Enterococcus faecalis. Hipoclorito de sódio. Acidificação. Clorexidina. Terapia por ultrassom 


\begin{abstract}
Objectives: The aim of this study was to analyze the influence of $\mathrm{pH}$ variation of irrigating solutions and ultrasonic agitation in intratubular cleanliness in bovine teeth contaminated by Enterococcus faecalis. Materials and methods: Ninety-six bovine incisor teeth were sterilized and infected with Enterococcus faecalis by a standardized protocol for a period of five days. The specimens were subjected to an irrigation protocol with $5 \mathrm{~mL}$ of sodium hypochlorite $(\mathrm{NaOCl}) 1 \%$ for five minutes with $\mathrm{pH} 5$ without ultrasonic agitation (G1); $\mathrm{NaOCl} 1 \%, \mathrm{pH} 5$ with ultrasonic agitation (G2); $\mathrm{NaOCl} 2.5 \%$, pH 5 without ultrasonic agitation (G3); $\mathrm{NaOCl} 2.5 \%$, pH5 with ultrasonic agitation (G4); $\mathrm{NaOCl} 1 \%, \mathrm{pH} 10$ without ultrasonic agitation (G5); $\mathrm{NaOCl} 1 \%, \mathrm{pH} 10$ with ultrasonic agitation (G6); $\mathrm{NaOCl} 2.5 \%$, pH10 without ultrasonic agitation (G7); $\mathrm{NaOCl} 2.5 \%$, pH10 with ultrasonic agitation (G8); Chlorhexidine (CLX) 2\% without ultrasonic agitation (G9); CLX with ultrasonic agitation (G10), composing ten test groups, besides to positive and negative controls. The specimens were analyzed using images with Bioimagel software acquired by confocal laser scanning microscope (CLSM) to quantify viable bacteria after irrigation. The Shapiro Wilk and D’ Agostino Pearson normality tests was performed, followed by Kruskal-Wallis and Dunn comparative tests $(p<0.05)$. Results: All groups decreased the number of viable bacterial cells compared to controls. The $\mathrm{NaOCl}$ group $\mathrm{pH} 5$ associated or not with ultrasonic agitation and CLX with ultrasonic agitation group reduced the amount of viable cells compared to the other groups. No one group eliminated completely Enterococcus faecalis from root canals. Conclusion: Therefore, the acidified $\mathrm{NaOCl}$ solution caused a significant decrease in the number of bacteria. The use of ultrasound promoted greater antimicrobial effectiveness associated to chlorhexidine.
\end{abstract}

Keywords: Enterococcus faecalis; Sodium hypochlorite; Acidification; Chlorhexidine; Ultrasonic Therapy 


\section{Introdução}

Os micro-organismos e seus produtos são o principal fator de desenvolvimento de doenças da polpa e periápice ${ }^{1}$. O tratamento endodôntico tem como principal objetivo a diminuição e controle desses micro-organismos ${ }^{2}$.

A fase de irrigação exerce o papel fundamental na movimentação ou solubilização do tecido pulpar, remoção dos micro-organismos, seus produtos e subprodutos, partículas teciduais ou estranhas ao canal e toxinas, permitindo a ação da medicação intracanal e consequentemente, facilitar o reparo ${ }^{3}$.

O hipoclorito de sódio $(\mathrm{NaOCl})$ tem sido largamente utilizado como auxiliar químico na desinfecção dos canais radiculares. É uma solução alcalina, que possui um duplo modo de ação: habilidade de dissolução de tecidos vivos ou necróticos, além da propriedade antimicrobiana devido à formação de compostos contendo cloro ativo, como o ácido hipocloroso $(\mathrm{HOCl})$ e o íon hipoclorito $(\mathrm{OCl}-)^{4}$. A solução de $\mathrm{NaOCl}$ com pH baixo favorece o aumento de $\mathrm{HOCl}$, o qual possui maior potencial desinfetante que o íon hipoclorito ${ }^{5}$. A clorexidina (CLX) também tem sido muito utilizada na Endodontia devido à sua excelente atividade antimicrobiana ${ }^{6}$, além de não possuir algumas das características indesejáveis do hipoclorito de sódio como instabilidade e forte irritação dos tecidos periapicais ${ }^{7}$. No entanto, sua desvantagem em relação ao $\mathrm{NaOCl}$ é que a $\mathrm{CLX}$ não apresenta capacidade de dissolução tecidual $^{8}$.

O sucesso do processo de irrigação depende tanto da ação física dos irrigantes quanto da sua capacidade química de dissolução tecidual ${ }^{9,10}$. Além disso, a ação física dos irrigantes ajuda a remover restos orgânicos, debris dentinários e micro-organismos do sistema de canais radiculares ${ }^{11}$ como a irrigação ultrassônica passiva (PUI), que tem se mostrado bastante efetiva ${ }^{12}$ sobre diversas situações.

Este tipo de irrigação é classificada como a forma mais eficiente de remover debris do sistema de canais radiculares, inclusive de regiões de istmo ${ }^{12,13}$ e dos canais laterais, reduzindo a população microbiana do sistema de canais, que apresentam áreas de difícil acesso devido a sua complexidade anatômica ${ }^{14}$.

Baseado nestas informações, justifica-se avaliar por meio de microscopia confocal de varredura a laser (MCVL), a influência da agitação ultrassônica na descontaminação intratubular dentinária de dentes bovinos por soluções de clorexidina a $2 \%$ e de hipoclorito de sódio a 1 e $2,5 \%$ com variações de $\mathrm{pH}$. 


\section{Material e Métodos}

\section{Obtenção dos espécimes e micro-organismos}

Foram selecionados 96 dentes bovinos unirradiculados recém-extraídos que foram submersos por 12 horas em hipoclorito de sódio para descontaminação inicial. Os dentes tiveram as coroas e os $5 \mathrm{~mm}$ (milímetros) apicais removidos em máquina metalográfica de corte ISOMET 1000 (Buehler Ltd Lake Bluff, IL, EUA) e padronizados em $12 \mathrm{~mm}$ de altura. As raízes foram instrumentadas até a lima K\#120 (Dentsply Maillefer, Suiça) e levadas à cuba ultrassônica (Cristófoli, Campo Mourão, Paraná, Brasil) para remoção de smear layer durante 15 minutos com ácido etileno diamino tetracético (EDTA) a 17\% (Biodinâmica Química e Farmacêutica Ltda., Ibiporã, PR, Brasil) e água deionizada em um segundo banho ultrassônico. Após a secagem, duas camadas de esmalte vermelho (L`Oréal Colorama, Rio de Janeiro, RJ, Brasil) foram aplicadas sobre a superfície externa dos espécimes. Os mesmos foram esterilizados com água destilada em microtubos de 1,5 mL (Axygen® Scientific, Union City, CA, EUA) em autoclave (Sercon, Modelo HG, Mogi das Cruzes, SP, Brasil), por $30 \mathrm{~min}$, a $121^{\circ} \mathrm{C}$ e a $1 \mathrm{~atm}$.

A linhagem de referência da bactéria Enterococcus faecalis (ATCC 29212) foi adquirida, e a morfologia colonial e coloração de Gram foram verificadas para confirmar a pureza da mesma algumas vezes ao longo do experimento. Os microorganismos foram cultivados em caldo $\mathrm{BHI}$ com subculturas sucessivas. As diluições foram feitas com base no valor de absorbância, obtido por espectrofotômetro (SF325NM, BelPhotonics do Brasil Ltda, Osasco, Brasil), a uma concentração de $3 x$ $10^{8}$ UFC / mL. A contaminação dos espécimes foi feita no período de cinco dias, em meio $\mathrm{BHI}$ a $37^{\circ} \mathrm{C}$, seguindo a sequência de centrifugações de Ma et al. $(2011)^{15}$ e o protocolo de Andrade et al. $(2015)^{16}$.

\section{Preparo das soluções irrigadoras}

Para o preparo das soluções irrigadoras foi utilizado solução de hipoclorito de sódio na concentração de 10 a 15\% (Synth®, LabSynth, Diadema, São Paulo, 
Brasil), a qual foi ajustada a concentração desejada (1 e 2,5\%). Os grupos testados estão descritos na Tabela 1. O controle positivo se refere ao grupo que foi contaminado e não foi submetido à irrigação e o controle negativo, as amostras não foram contaminadas e foram irrigadas. Para o ajuste do $\mathrm{pH}$ foi adicionado ácido acético (Merck S.A Indústria Químicas, Rio de Janeiro, RJ, Brasil) nas soluções, avaliadas em pHmetro (Orion 3 Star, Thermo Fisher Scientific Inc., Ayer Rajah Crescent, Singapura). Para cada valor de $\mathrm{pH}$ desejado, foram adicionadas as respectivas substâncias tampão: acetato de sódio (Synth $\circledast$, LabSynth, Diadema, São Paulo, Brasil) para o pH 5 e Glicina (Bio Rad Laboratories Inc., Hercules, CA, EUA) para o $\mathrm{pH}$ 10. As concentrações e os valores de $\mathrm{pHs}$ foram ajustados de acordo com cálculos e fórmulas químicas adequadas.

Após o término do preparo, as soluções passaram por titulometria para confirmação da concentração de cloro e então foram acondicionadas em frascos âmbar, devidamente etiquetados e identificados, que foram armazenados em geladeira a $2^{\circ} \mathrm{C}$. Cada solução foi preparada individualmente e no dia do experimento.

Tabela 1: Distribuição dos grupos experimentais

\begin{tabular}{cl}
\hline Grupos & \multicolumn{1}{c}{ Solução irrigadora } \\
\hline G1 & Hipoclorito de sódio 1\% pH5 (NaOCl 1\% pH5) \\
G2 & Hipoclorito de sódio 1\% pH5 + Ultrassom (NaOCl 1\% pH5 + US) \\
G3 & Hipoclorito de sódio 2,5\% pH5 (NaOCl 2,5\% pH5) \\
G4 & Hipoclorito de sódio 2,5\% pH5 + Ultrassom (NaOCl 2,5\% pH5 + US) \\
G5 & Hipoclorito de sódio 1\% pH10 (NaOCl 1\% pH10) \\
G6 & Hipoclorito de sódio 1\% pH10 + Ultrassom (NaOCl 1\% pH10 + US) \\
G7 & Hipoclorito de sódio 2,5\% pH10 (NaOCl 2,5\% pH10) \\
G8 & Hipoclorito de sódio 2,5\% pH10 + Ultrassom (NaOCl 2,5\% pH10 + US) \\
G9 & Clorexidina 2\%(CLX) \\
G10 & Clorexidina 2\% + US (CLX+ US) \\
& CONTROLE POSITIVO \\
& CONTROLE NEGATIVO
\end{tabular}


Os espécimes foram fixados em um dispositivo de apoio esterilizado dentro de câmara de fluxo laminar e tiveram seu ápice selado com restaurador provisório (Coltosol, Coltene, Suíça). Com o auxílio de uma pipeta, $500 \mu \mathrm{L}$ da solução irrigadora foi depositada dentro de uma seringa de irrigação e em seguida inserida no canal em toda sua extensão, onde permaneceram por cinco minutos. Nos grupos onde foi realizada agitação ultrassônica foi utilizado o equipamento de ultrassom modelo PM200 (Piezon® Master 200, EMS, Suíça) e insertos modelo E1 irrissonic (Helse Dental Technology, Santa Rosa de Viterbo, São Paulo, Brasil) e ela foi realizada no inicio dos cinco minutos. Os insertos foram esterilizados previamente e acoplados diretamente ao ultrassom, foram introduzidas no canal à $1 \mathrm{~mm}$ do comprimento de dente e agiram no canal por 20 segundos em uma potência de $20 \%$ como recomenda o fabricante, em cada sentido (vestíbulo-palatino e mésio-distal) contados com um cronômetro digital. Após a irrigação com as soluções em teste, os espécimes receberam uma irrigação com $500 \mu \mathrm{L}$ de solução salina esterilizada seguida de $500 \mu \mathrm{L}$ de tiossulfato de sódio a $5 \%$ no caso dos grupos com hipoclorito de sódio e Tween 80 com leticina de soja 0,7\% para os grupos irrigados com clorexidina (Farmácia de manipulação Formulare, Bauru, São Paulo, Brasil), durante 5 minutos, visando neutralizar o efeito residual das soluções em teste. Ao final, os espécimes receberam uma irrigação com $500 \mu \mathrm{L}$ de solução salina esterilizada.

Após a irrigação, os espécimes foram seccionados longitudinalmente com auxílio de uma máquina de corte, sob refrigeração. Em seguida foram colocados em placa de cultura celular de 24 poços para remoção da smear layer com EDTA a 17\% durante cinco minutos e, posteriormente, lavados com $500 \mu \mathrm{L}$ de solução salina esterilizada. Na sequência, os espécimes foram corados por um período de vinte minutos com $30 \mu \mathrm{L}$ de LIVE/DEAD ${ }^{\circledR}$ BacLight $^{\mathrm{TM}}$ Bacterial Viability Kit (Invitrogen Molecular Probes, Eugene, OR,EUA), que contem o corante verde SYTO ${ }^{\circledR} 9$ e o corante vermelho iodeto de propídio, corando assim as bactérias vivas (verde) e mortas (vermelho) respectivamente.

Os espécimes foram visualizados em MCVL Leica TCS- SPE (Leica Microsystems $\mathrm{GmbH}$, Mannheim, Alemanha) totalizando oito imagens por espécime de modo sequencial, nas áreas de terço cervical e médio e superficial e profunda da dentina. A área superficial se refere a porção de dentina mais próxima ao canal e a profunda $250 \mu \mathrm{m}$ da região superficial em direção à porção externa. O escaneamento foi realizado com uma objetiva de $40 \mathrm{X}$, a cada $1 \mu \mathrm{M}$ de profundidade 


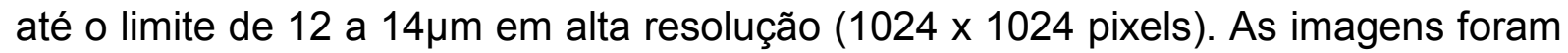
adquiridas por meio do programa Leica Application Suitte-Advanced Fluorescence (LAS AF, Leica Mannhein, Alemanha) e levadas ao software Leica AF Lite para a fragmentação das camadas de cada imagem. No programa bioimageL $\mathrm{v} 2-1^{17}$, as bactérias vivas e mortas foram quantificadas por meio da fluorêscencia verde (viva) e vermelha (morta) emitida pelas mesmas nas imagens avaliadas. 


\section{Análise estatística}

Os dados obtidos por meio do software BiolmageL, relacionados à porcentagem de bactérias viáveis, não apresentaram normalidade por meio do teste de D'Agostino e Shapiro Wilk, sendo então submetidos ao Teste não paramétrico de Kruskal-Wallis seguido de Dunn ( $p>0,05)$.

\section{Resultados}

Todos os grupos irrigados mostraram redução bacteriana significativa na dentina contaminada quando comparada ao grupo controle positivo $(p<0,05)$ (Figura 1). O grupo da clorexidina associada à agitação ultrassônica juntamente com os grupos de hipoclorito de sódio com pH 5 foram estatisticamente melhores que os outros, de um modo geral (Tabela 2).

Ao avaliar a região superficial e profunda todos os grupos reduziram a quantidade de células bacterianas viáveis em relação ao controle positivo, com exceção do grupo $\mathrm{NaOCl} 1 \%$ pH10 $(p>0,05)$. O grupo da clorexidina associado a agitação ultrassônica foi o que mais reduziu a quantidade de células bacterianas viáveis $(p<0,05)$ juntamente com os grupos $\mathrm{NaOCl} p H 5$ associados ou não ao ultrassom.

No terço cervical, o grupo da clorexidina associada à agitação ultrassônica foi o que mais reduziu o número de células viáveis $(p<0,05)$ junto com os grupos de $\mathrm{NaOCl}$ com pH5, onde entre eles não houve diferença estatística. O grupo $\mathrm{NaOCl}$ $1 \% \mathrm{pH} 5$ só teve diferença com o grupo $\mathrm{NaOCl} 1 \% \mathrm{pH} 10(\mathrm{p}<0,05)$. Todos os grupos foram diferentes estatisticamente do controle com exceção dos grupos da clorexidina, $\mathrm{NaOCl}$ 2,5\% pH 10 associado ao ultrassom e $\mathrm{NaOCl} 1 \% \mathrm{pH} 10$ ( p>0,05).

No terço médio não houve diferença estatística entre os grupos, todos reduziram estatisticamente o número de células viáveis em relação ao controle com exceção do $\mathrm{NaOCl} 1 \%$ pH10 ( $p>0,05)$. 
Tabela 2 - Grupos que apresentaram diferenças significativas pela análise da viabilidade celular, em porcentagem pela área analisada, após aplicação dos testes estatísticos de Kruskal Wallis- Dunn $(p<0.05)$.

\begin{tabular}{|c|c|}
\hline Grupos & Mediana \\
\hline CLX US & $0,13(0,00-9,17)^{\mathrm{e}}$ \\
\hline $\mathrm{NaOCl} 2,5 \%$ pH 5 US & $0,69(0,00-7,37)^{\mathrm{de}}$ \\
\hline $\mathrm{NaOCl} 1 \% \mathrm{pH} 5$ & $0,75(0,10-24,83)^{\mathrm{cde}}$ \\
\hline $\mathrm{NaOCl} 2,5 \% \mathrm{pH} 5$ & $0,79(0,00-4,54)^{\mathrm{de}}$ \\
\hline $\mathrm{NaOCl} 1 \% \mathrm{pH} 5$ US & $0,86(0,02-4,92)^{\mathrm{de}}$ \\
\hline $\mathrm{NaOCl} 1 \% \mathrm{pH} 10$ US & $2,34(0,24-16,98)^{\mathrm{bcd}}$ \\
\hline CLX & $3,72(0,02-27,85)^{b c}$ \\
\hline $\mathrm{NaOCl} 2,5 \% \mathrm{pH} 10$ US & $3,87(0,10-13,18)^{b c}$ \\
\hline $\mathrm{NaOCl} 2,5 \% \mathrm{pH} 10$ & $4,56(0,36-23,51)^{b c}$ \\
\hline $\mathrm{NaOCl} 1 \% \mathrm{pH} 10$ & $4,63(0,37-23,90)^{b}$ \\
\hline CONTROLE POSITIVO & $72,03(29,28-94,61)^{a}$ \\
\hline
\end{tabular}

*Letras diferentes representam diferença estatística significante $(p<0,05)$ 

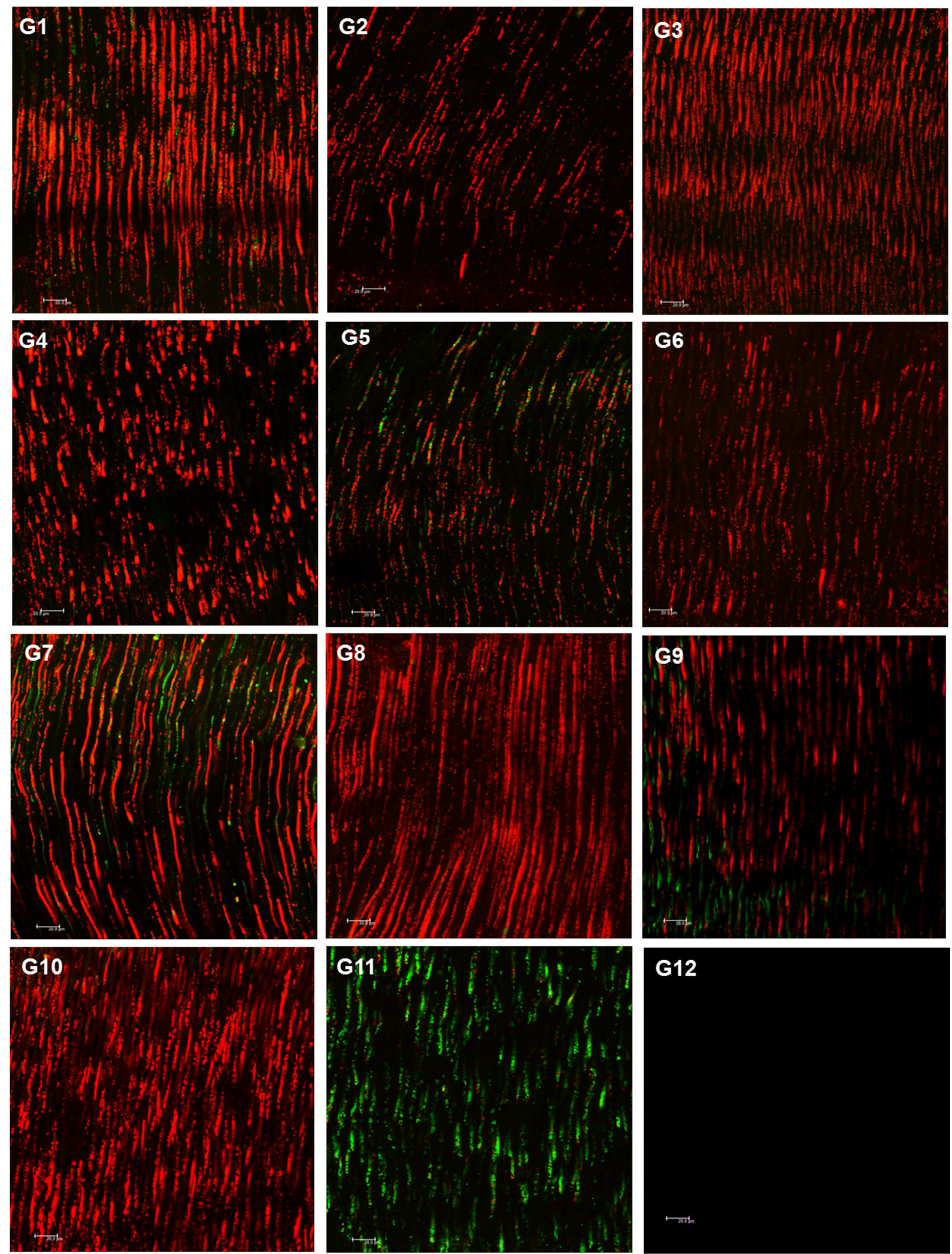

\section{G12}

Figura 1: Imagens representativas dos espécimes após irrigação $\mathrm{G} 1: \mathrm{NaOCl} 1 \%$ pH5; G2: NaOCl 1\% pH5 + US; G3: NaOCl 2,5\% pH5; G4: NaOCl 2,5\% pH5 + US; G5: $\mathrm{NaOCl} 1 \% \mathrm{pH} 10 ; \mathrm{G} 6: \mathrm{NaOCl} 1 \% \mathrm{pH} 10$ + US; G7: NaOCl 2,5\% pH10; G8: $\mathrm{NaOCl}$ 2,5\% pH10 + US; G9: CLX; G10: CLX + US; G11: Controle positivo; G12: Controle negativo. 



\section{Discussão}

O presente estudo avaliou o efeito de soluções de hipoclorito de sódio com variações de $\mathrm{pH}$ e digluconato de clorexidina associado ou não ao ultrassom na desinfecção de canais radiculares de dentes bovinos.

Enterococcus faecalis é uma bactéria comumente encontrada em casos de fracassos endodônticos ${ }^{18,19,20}$, possui capacidade de invadir túbulos dentinários e permanece viável dentro deles ${ }^{21,22,23}$ além de possuir uma resistência a várias substâncias antimicrobianas e sobreviver em ambiente alcalino ${ }^{24}$ e não ser totalmente eliminado do canal radicular ${ }^{25}$.

A contaminação dos espécimes foi realizada pelo protocolo de Andrade et al. $(2015)^{16}$ adaptado de Haapasalo; Orstavik $(1987)^{26}$ e ciclos de centrifugação propostos por Ma et al.(2011) ${ }^{15}$. O modelo experimental utilizado foi escolhido a fim de simular uma situação endodôntica real, onde ocorre infecção em profundidade nos túbulos dentinários. Foram utilizados dentes bovinos pela semelhança com a estrutura dentinária humana ${ }^{27}$.

A irrigação atua no preparo biomecânico não só como lubrificante, mas na remoção de detritos e na eliminação de bactérias do interior canal radicular $^{28}$. $\mathrm{O}$ hipoclorito de sódio é a substância mais utilizada na endodontia por suas diversas propriedades como ação solvente de matéria orgânica e excelente atividade antimicrobiana, porém diversos autores mostram que ele não é capaz de eliminar completamente os enterococos do canal ${ }^{25}$.

Apesar de escassos, estudos anteriores ${ }^{29,30,31}$ mostram que a redução do pH (acidificação) do $\mathrm{NaOCl}$ sugerem que sua capacidade antimicrobiana é aumentada, corroborando a presente pesquisa. Os grupos onde o $\mathrm{pH}$ foi reduzido a 5 , independente da concentração (1\% ou 2,5\%), obtiveram melhores resultados quando comparados às soluções de hipoclorito de sódio com pH 10. Essa maior capacidade antimicrobiana se deve pela maior liberação de ácido hipocloroso que, quando em contato com tecido orgânico atua como um solvente que libera cloro. $O$ cloro apresenta uma ação antimicrobiana de inibição enzimas bacterianas levando a uma oxidação irreversível de enzimas essenciais ${ }^{32,4}$.

Para reduzir o pH da solução de hipoclorito foi utilizado o ácido acético devido a sua atividade antibacteriana, segurança e estabilidade da concentração de cloro disponível ${ }^{33}$. As misturas com outros ácidos (ácido lático e cítrico) consomem o cloro 
disponível e reduzem a atividade bactericida do desinfetante ${ }^{33,25}$. Apesar disso, na presente pesquisa, foi encontrada falta da estabilidade do cloro disponível nas soluções através de estudos-piloto verificando sua titulometria. As soluções teste foram preparadas no mesmo dia do uso para evitar alteração na concentração de cloro e para manter o pH estável foi utilizada uma substância tampão, acetato de sódio para as soluções de $\mathrm{pH} 5$ e glicina para as de $\mathrm{pH} 10$, que mantiveram o pH estável por até 14 dias.

A irrigação ultrassônica passiva vem sendo proposta como alternativa para potencializar a limpeza do canal $^{34}$. A associação do hipoclorito de sódio com PUI aumentou a eficácia intratubular na eliminação do Enterococcus faecalis em todos os grupos, como já demonstrado em estudos prévios ${ }^{35}$. Os grupos de hipoclorito de sódio em pH 5 mostram uma capacidade ainda maior, diferente estatisticamente dos grupos de hipoclorito com pH 10 (básico) confirmando o maior efeito antibacteriano quando é reduzido o $\mathrm{pH}$ da solução ${ }^{30}$.

O digluconato de clorexidina é um agente antimicrobiano de amplo espectro com ação comparável ao hipoclorito de sódio ${ }^{36,37}$, além de não possuir algumas das características indesejáveis deste, como instabilidade e forte irritação dos tecidos periapicais, porém, não tem capacidade de dissolução de matéria orgânica. Por esse motivo Zender $(2006)^{38}$ recomendou o uso associado do hipoclorito de sódio e clorexidina durante o tratamento endodôntico, a fim de potencializar o efeito antibacteriano.

Essas substâncias quando misturadas reagem formando um precipitado de cor marrom-acastanhada ${ }^{39}$ que contém para-cloroanilina (PCA $)^{40}$. Estudos mostram que essa substância é tóxica e que ela pode ter potencial carcinogênico ${ }^{41}$.

No presente estudo, o grupo da clorexidina sem ultrassom apresentou resultados semelhantes ao hipoclorito de sódio $\mathrm{pH} 10$. O grupo que associou o digluconato de clorexidina com agitação ultrassônica foi o que apresentou resultados estatisticamente semelhantes aos dos grupos de hipoclorito pH5. Um estudo de Cameron (1988) ${ }^{42}$ mostra que a agitação ultrassônica provoca aumento de temperatura no canal radicular, que pode chegar até 45 graus. O aumento da temperatura provocado pela agitação ultrassônica viabiliza a formação da paracloroanilina e outros isômeros de anilina como 2- cloroanilina, 3 cloroanilina e todos são tóxicos ${ }^{43}$. Com a produção destas substâncias tóxicas, mais radicais oxidantes são liberados e também irão exercer efeito letal às bactérias. Possivelmente estas 
substâncias tóxicas potencializem o maior efeito, justificando a maior ação do grupo que associa clorexidina com ultrassom. No entanto, ao eliminar mais microorganismos, esta associação também será lesiva às células do hospedeiro, o que não é recomendável.

Pelos resultados obtidos, onde observa-se a maior capacidade antimicrobiana do hipoclorito de sódio quando é reduzido seu pH para 5, sugere-se sua utilização na clínica como irrigante final antes da obturação complementando a atividade antimicrobiana para o êxito do tratamento.

\section{Conclusão}

Baseado nos resultados obtidos a associação da agitação ultrassônica com soluções de hipoclorito de sódio com redução de pH propiciou uma redução do número de bactérias viáveis, porem não significantemente maior que o uso da solução utilizada sem agitação, confirmando o efeito antimicrobiano superior das soluções irrigadoras com diminuição do $\mathrm{pH}$. O uso do ultrassom promoveu maior efetividade antimicrobiana no irrigante clorexidina.

\section{Referências}

1. Siqueira JF Jr. Aetiology of root canal treatment failure: why well-treated teeth can fail. Int Endod J 2001;34:1-10.

2. Ricucci D, Siqueira JF Jr, Bate AL, Pitt Ford TR. Histologic investigation of root canal-treated teeth with apical periodontitis: a retrospective study from twentyfour patients. J Endod. 2009;35(4):493-502.

3. van der Sluis LW, Vogels MP, Verhaagen B, Macedo R, Wesselink PR. Study on the influence of refreshment/activation cycles and irrigants on mechanical cleaning efficiency during ultrasonic activation of the irrigant. $\mathrm{J}$ Endod. 2010;36(4):737-40.

4. Lopes HP, Siqueira Jr. JF. Endodontia Biológica e técnica. 3ed:Guanabara Koogan; 2010 
5. Bremer PJ, Monk I, Butler R. Inactivation of Listeria monocytogenes/Flavobacterium spp. biofilms using chlorine: impact of substrate, pH, time and concentration. Lett Appl Microbiol. 2002;35(4):321-5.

6. Carbajal Mejia JB. Antimicrobial effects of calcium hydroxide, chlorhexidine, and propolis on Enterococcus faecalis and Candida albicans. J Investig Clin Dent. 2013.

7. Bramante CM, Duque JA, Cavenago BC, Vivan RR, Bramante AS, de Andrade FB, et al. Use of a 660-nm Laser to Aid in the Healing of Necrotic Alveolar Mucosa Caused by Extruded Sodium Hypochlorite: A Case Report. J Endod. 2015;41(11):1899-902.

8. Naenni N, Thoma K, Zehnder M. Soft tissue dissolution capacity of currently used and potential endodontic irrigants. J Endod. 2004;30(11):785-7.

9. Abou-Rass M, Piccinino MV. The effectiveness of four clinical irrigation methods on the removal of root canal debris. Oral Surg Oral Med Oral Pathol. 1982;54(3):323-8.

10. Lee SJ, Wu MK, Wesselink PR. The effectiveness of syringe irrigation and ultrasonics to remove debris from simulated irregularities within prepared root canal walls. Int Endod J. 2004;37(10):672-8.

11. Baker NA, Eleazer PD, Averbach RE, Seltzer S. Scanning electron microscopic study of the efficacy of various irrigating solutions. J Endod. 1975;1(4):127-35.

12. Alves FR, Almeida BM, Neves MA, Moreno JO, Rocas IN, Siqueira JF, Jr. Disinfecting oval-shaped root canals: effectiveness of different supplementaryapproaches. J Endod. 2011;37(4):496-501.

13. Rodig T, Sedghi M, Konietschke F, Lange K, Ziebolz D, Hulsmann M. Efficacy of syringe irrigation, RinsEndo and passive ultrasonic irrigation in removing debris from irregularities in root canals with different apical sizes. Int Endod J. 2010;43(7):581-9.

14. Klyn SL, Kirkpatrick TC, Rutledge RE. In vitro comparisons of debris removal of the EndoActivator system, the $\mathrm{F}$ file, ultrasonic irrigation, and $\mathrm{NaOCl}$ irrigation 
alone after hand-rotary instrumentation in human mandibular molars. J Endod. 2010;36(8):1367-71.

15. Ma J, Wang Z, Shen Y, Haapasalo M. A new noninvasive model to study the effectiveness of dentin disinfection by using confocal laser scanning microscopy. J Endod. 2011;37(10):1380-5.

16. Andrade FB, Arias MP, Maliza AG, Duarte MA, Graeff MS, Amoroso-Silva PA, et al. A new improved protocol for in vitro intratubular dentinal bacterial contamination for antimicrobial endodontic tests: standardization and validation by confocal laser scanning microscopy. J Appl Oral Sci. 2015;23(6):591-8.

17. Chávez de Paz LE, Bergenholtz G, Svensäter G. The effects of antimicrobials on endodontic biofilm bacteria. J Endod. 2010;36(1):70-7.

18. Peciuliene V, Reynaud AH, Balciuniene I, Haapasalo M. Isolation of yeasts and enteric bacteria in root-filled teeth with chronic apical periodontitis. Int Endod J. 2001;34(6):429-34.

19. Pinheiro ET, Gomes BP, Ferraz CC, Sousa EL, Teixeira FB, Souza-Filho FJ. Microorganisms from canals of root-filled teeth with periapical lesions. Int Endod J. 2003;36(1):1-11.

20. Stuart $\mathrm{CH}$, Schwartz SA, Beeson TJ, Owatz CB. Enterococcus faecalis: its rolein root canal treatment failure and current concepts in retreatment. $J$ Endod.2006;32(2):93-8.

21. Siqueira JF Jr, De Uzeda M, Fonseca ME. A scanning electron microscopic evaluation of in vitro dentinal tubules penetration by selected anaerobic bacteria. J Endod. 1996;22(6):308-10.

22. Love RM. Enterococcus faecalis--a mechanism for its role in endodontic failure. Int Endod J. 2001;34(5):399-405.

23. Chivatxaranukul P, Dashper SG, Messer HH. Dentinal tubule invasion and adherence by Enterococcus faecalis. Int Endod J. 2008;41(10):873-82. 
24. Nakajo K, Komori R, Ishikawa S, Ueno T, Suzuki Y, Iwami Y, et al. Resistance to acidic and alkaline environments in the endodontic pathogen Enterococcus faecalis. Oral Microbiol Immunol. 2006;21(5):283-8.

25. Guerreiro-Tanomaru JM, Morgental RD, Flumignan DL, Gasparini F, Oliveira JE, Tanomaru-Filho M. Evaluation of $\mathrm{pH}$, available chlorine content, and antibacterial activity of endodontic irrigants and their combinations against Enterococcus faecalis. Oral Surg Oral Med Oral Pathol Oral Radiol Endod. 2011;112(1):132-5.

26. Haapasalo M, Orstavik D. In vitro infection and disinfection of dentinal tubules. J Dent Res. 1987;66(8):1375-9.

27. Evans M, Davies JK, Sundqvist G, Figdor D. Mechanisms involved in the resistance of Enterococcus faecalis to calcium hydroxide. Int Endod J. 2002;35(3):221-8.

28. van der Sluis LW, Versluis M, Wu MK, Wesselink PR. Passive ultrasonic irrigation of the root canal: a review of the literature. Int Endod $\mathrm{J}$. $2007 ; 40(6): 415-26$.

29. Siqueira JF Jr, Machado AG, Silveira RM, Lopes HP, de Uzeda M. Evaluation of the effectiveness of sodium hypochlorite used with three irrigation methods in the elimination of Enterococcus faecalis from the root canal, in vitro. Int Endod J. 1997;30(4):279-82.

30. Mercade M, Duran-Sindreu F, Kuttler S, Roig M, Durany N. Antimicrobial efficacy of $4.2 \%$ sodium hypochlorite adjusted to $\mathrm{pH} 12,7.5$, and 6.5 in infected human root canals. Oral Surg Oral Med Oral Pathol Oral Radiol Endod. 2009;107(2):295-8.

31. del Carpio-Perochena A, Bramante CM, de Andrade FB, Maliza AG, Cavenago BC, Marciano MA, et al. Antibacterial and dissolution ability of sodium hypochlorite in different pHs on multi-species biofilms. Clin Oral Investig. 2015;19(8):2067-73.

32. Estrela C, Estrela CR, Barbin EL, Spanó JC, Marchesan MA, Pécora JD. Mechanism of action of sodium hypochlorite. Braz Dent J. 2002;13(2):113-7. 
33. Kuroiwa K, Nakayama H, Kuwahara T, Tamagawa K, Hattori K, Murakami K, et al. Augmenting effect of acetic acid for acidification on bactericidal activity of hypochlorite solution. Lett Appl Microbiol. 2003;36(1):46-9.

34. van der Sluis LW, Versluis M, Wu MK, Wesselink PR. Passive ultrasonic irrigation of the root canal: a review of the literature. Int Endod $\mathrm{J}$. 2007;40(6):415-26.

35. de Almeida AP, Souza MA, Miyagaki DC, Dal Bello Y, Cecchin D, Farina AP. Comparative evaluation of calcium hypochlorite and sodium hypochlorite associated with passive ultrasonic irrigation on antimicrobial activity of a root canal system infected with Enterococcus faecalis: an in vitro study. J Endod. 2014 Dec;40(12):1953-7.

36. White RR, Hays GL, Janer LR. Residual antimicrobial activity after canal irrigation with chlorhexidine. J Endod. 1997;23(4):229-31.

37. Siqueira JF Jr, Batista MM, Fraga RC, de Uzeda M. Antibacterial effects of endodontic irrigants on black-pigmented gram-negative anaerobes and facultative bacteria. J Endod. 1998;24(6):414-6.

38. Zehnder M. Root canal irrigants. J Endod. 2006;32(5):389-98.

39. Basrani BR, Manek S, Sodhi RN, Fillery E, Manzur A. Interaction between sodium hypochlorite and chlorhexidine gluconate. J Endod. 2007;33(8):966-9.

40. Heard DD, Ashworth RW. The colloidal properties of chlorhexidine and its interaction with some macromolecules. J Pharm Pharmacol. 1968;20(7):505-12

41. Chhabra RS, Huff JE, Haseman JK, Elwell MR, Peters AC. Carcinogenicity of pchloroaniline in rats and mice. Food Chem Toxicol. 1991;29(2):119-24.

42. Cameron JA. The effect of ultrasonic endodontics on the temperature of the root canal wall. J Endod. 1988;14(11):554-9.

43. Basrani BR, Manek S, Fillery E. Using diazotization to characterize the effect of heat or sodium hypochlorite on 2.0\% chlorhexidine. J Endod. 2009; 35(9):12969. 



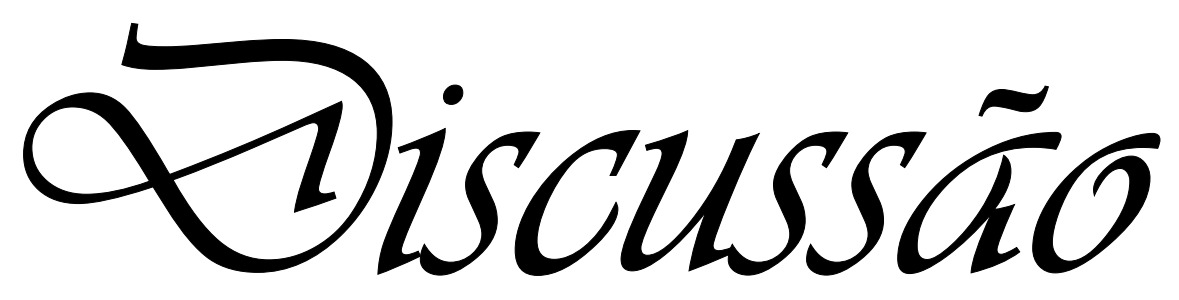





\section{DISCUSSÃO}

Para avaliação e quantificação das bactérias viáveis foi utilizado o MCVL que verifica a viabilidade bacteriana mediante o uso de corantes específicos apesar da leitura em profundidade ser pequena (ORDINOLA- ZAPATA, 2009).

Enterococcus faecalis foi escolhido no presente estudo porque é uma bactéria comumente encontrada em casos de fracassos endodônticos (PECIULIENE et al., 2001; PINHEIRO et al., 2003; STUART et al., 2006) pois possui capacidade de invadir túbulos dentinários e permanecer viável dentro deles (SIQUEIRA; UZEDA; FONSECA, 1996; LOVE 2001; CHIVATXARANUKUL; DASHPER ; MESSER, 2008), além de possuir uma resistência a várias substâncias antimicrobianas e sobreviver em ambiente alcalino (NAKAJO et al, 2006) e não ser totalmente eliminado do canal radicular (GUERREIRO-TANOMARU et al., 2011).

A contaminação dos espécimes foi realizada pelo protocolo de Andrade et al. (2015) adaptado de Haapasalo; Orstavik (1987) e ciclos de centrifugação propostos por Ma et al. (2011), com uma duração total de cinco dias afim de manter as células bacterianas viáveis. O modelo experimental utilizado foi escolhido a fim de simular uma situação endodôntica real, onde ocorre infecção em profundidade nos túbulos dentinários. Foram utilizados dentes bovinos pela semelhança com a estrutura dentinária humana (EVANS et al., 2002, CAMARGO et al., 2007).

A irrigação atua no preparo biomecânico não só como lubrificante, mas na remoção de detritos e na eliminação de bactérias do interior canal radicular. A irrigação ultrassônica passiva vem sendo proposta como alternativa para potencializar a limpeza do sistema de canais radiculares (VAN DER SLUIS et al., 2007).Ela tem o potencial de remover restos de dentina, tecido orgânico e bactérias de áreas que são inacessíveis à instrumentação e á irrigação convencional. Tal fato pode ser explicado em função dos fenômenos físicos que ocorrem entre o inserto ultrassônico e o irrigante. Tais fenômenos seriam cavitação transitória, microvaporização acústica e shock wave (VAN DER SLUIS et al., 2007), que podem favorecer a chegada da solução irrigante a profundidades da dentina que a irrigação convencional não é capaz. 
$\mathrm{Na}$ presente pesquisa o inserto ultrassônico foi utilizado por 20 segundos em cada sentido do canal, mésio-distal e vestíbulo-palatino (totalizando 40 segundos de ativação) para que não houvesse vantagens para nenhum dos sentidos. $O$ tempo de 20 segundos foi determinado baseado em protocolos já utilizados na endodontia (VAN DER SLUIS et al., 2010; MOZO et al., 2014).

O volume na solução irrigadora pode influenciar na limpeza dos canais radiculares (WU et al., 1997). Na presente pesquisa foi utilizada uma quantidade de $500 \mu \mathrm{L}$ de solução irrigadora para todos os grupos. O canal principal ficou totalmente preenchido com a solução irrigadora, pois o objetivo era saber o real efeito químico de cada solução sem que a quantidade de irrigante influenciasse.

O hipoclorito de sódio é a substância mais utilizada na endodontia por suas diversas propriedades como ação solvente de matéria orgânica e excelente atividade antimicrobiana, porém diversos autores mostram que ele não é capaz de eliminar completamente Enterococos faecalis do canal (GUERREIRO-TANOMARU et al., 2011)

Apesar de escassos, estudos anteriores (SIQUEIRA et al. 1997, MERCADE et al. 2009, DEL CARPIO PEROCHENA et al. 2011) mostram que a redução do pH (acidificação) do $\mathrm{NaOCl}$ sugerem que sua capacidade antimicrobiana é aumentada, corroborando a presente pesquisa. Os grupos onde o $\mathrm{pH}$ foi reduzido a 5 , independente da concentração ( $1 \%$ ou $2,5 \%$ ), obtiveram melhores resultados quando comparados às soluções de hipoclorito de sódio com pH 10. Essa maior capacidade antimicrobiana se deve pela maior liberação de ácido hipocloroso que, quando em contato com tecido orgânico atua como um solvente que libera cloro. $O$ cloro apresenta uma ação antimicrobiana de inibição de enzimas bacterianas levando a uma oxidação irreversível de enzimas essenciais (ESTRELA, LOPES E SIQUEIRA Jr, 2010).

A acidificação do hipoclorito reduz a sua capacidade de dissolução tecidual (DEL CARPIO PEROCHENA et al., 2015), portanto deve somente ser utilizada quando tecidos pulpares vivos e necróticos já tiverem sido dissolvidos através do hipoclorito com pH alcalino e, portanto, sua indicação seria para irrigação final para aumentar o efeito antibacteriano 
Para reduzir o pH da solução de hipoclorito foi utilizado o ácido acético devido a sua atividade antibacteriana, segurança e estabilidade da concentração de cloro disponível (KUROIWA et al., 2003). As misturas com outros ácidos (ácido lático e cítrico) consomem o cloro disponível e reduzem a atividade bactericida do desinfetante (KUROIWA et al., 2003; GUERREIRO-TANOMARU et al. 2011). Apesar disso, na presente pesquisa, foi encontrada falta da estabilidade do cloro disponível nas soluções através de estudos-piloto verificando sua titulometria. As soluções teste foram preparadas no mesmo dia do uso para evitar alteração na concentração de cloro e para manter o pH estável foi utilizada uma substância tampão, acetato de sódio para as soluções de pH 5 e glicina para as de $\mathrm{pH} 10$, que mantiveram o pH estável por até 14 dias.

A associação do hipoclorito de sódio com PUI aumentou a eficácia intratubular na eliminação do Enterococcus faecalis em todos os grupos, como já demonstrado em estudos prévios (ALMEIDA et al., 2014). Os grupos de hipoclorito de sódio em pH 5 mostram uma capacidade ainda maior, diferente estatisticamente dos grupos de hipoclorito com pH 10 (básico) confirmando o maior efeito antibacteriano quando é reduzido o pH da solução (MERCADE et al, 2009)

O digluconato de clorexidina é um agente antimicrobiano de amplo espectro com ação comparável ao hipoclorito de sódio (WHITE et al. 1997, SIQUEIRA JR et al. 1998), além de não possuir algumas das características indesejáveis deste, como instabilidade e irritação dos tecidos periapicais, porém, não possui capacidade de dissolução de matéria orgânica. Por esse motivo Zender (2006) recomendou o uso associado do hipoclorito de sódio e clorexidina durante o tratamento endodôntico, a fim de potencializar o efeito antibacteriano.

Essas substâncias quando misturadas reagem formando um precipitado de cor marrom-acastanhada (BASRANI et al., 2007) que contém para-cloroanilina (PCA) (HEARD; ASHWORTH., 1968). Estudos mostram que essa substância é tóxica e que ela pode ter potencial carcinogênico (CHHABRA et al., 1991).

No presente estudo, o grupo da clorexidina sem ultrassom apresentou resultados semelhantes ao hipoclorito de sódio $\mathrm{pH} 10$. O grupo que associou o digluconato de clorexidina com agitação ultrassônica foi o que apresentou resultados estatisticamente semelhantes aos dos grupos de hipoclorito pH5. Um estudo de 
Cameron (1988) mostra que a agitação ultrassônica provoca aumento de temperatura no canal radicular, que pode chegar até 45 graus. O aumento da temperatura provocado pela agitação ultrassônica viabiliza a formação da paracloroanilina e outros isômeros de anilina como 2- cloroanilina, 3 cloroanilina e todos são tóxicos (BASRANI et al., 2009). Com a produção destas substâncias tóxicas, mais radicais oxidantes são liberados e também irão exercer efeito letal às bactérias. Possivelmente estas substâncias tóxicas potencializem o maior efeito, justificando a maior ação do grupo que associa clorexidina com ultrassom. No entanto, ao eliminar mais micro-organismos, esta associação também será lesiva às células do hospedeiro, o que não é recomendável.

O hipoclorito de sódio em $\mathrm{pH}$ ácido tem mostrado um efeito antibacteriano maior do que em pH alcalino (MERCADE et al., 2009; GUERREIRO - TANOMARU et al., 2011; DEL CARPIO PEROCHENA et al., 2015). O trabalho de Maliza em 2013 mostrou que soluções de $\mathrm{NaOCl}$ acidificadas mesmo em menores concentrações proporcionaram maior morte microbiana intradentinária, igualando seu efeito às soluções mais concentradas. Como soluções acidificadas possuem menor capacidade de dissolução tecidual (DEL CARPIO PEROCHENA et al., 2011), recomendou-se o uso das soluções acidificadas como irrigante final (MALIZA et al., 2013). Desta forma, não seria necessária a utilização da clorexidina após o uso de $\mathrm{NaOCl}$ evitando a possível formação deste precipitado insolúvel. 


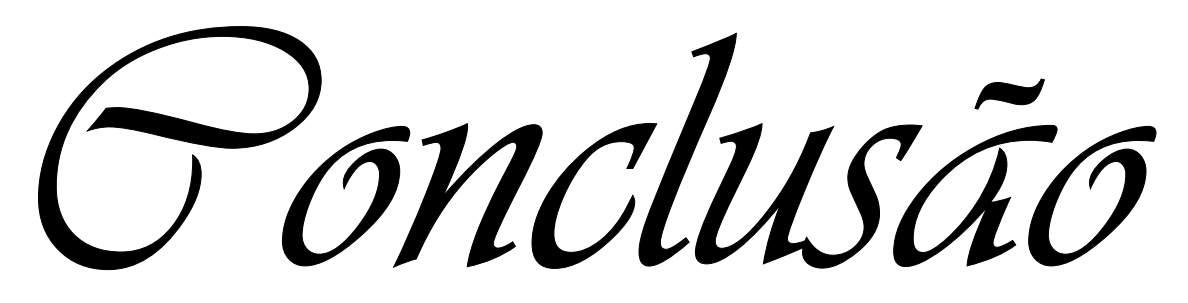





\section{CONCLUSÃO}

Baseado nos resultados obtidos a agitação ultrassônica de soluções de hipoclorito de sódio com redução de $\mathrm{pH}$ propiciou uma redução do número de bactérias viáveis, porem não significantemente maior que o uso da solução utilizada sem agitação, confirmando o efeito antimicrobiano superior das soluções irrigadoras com diminuição do $\mathrm{pH}$. Por outro lado, o efeito antimicrobiano da clorexidina foi potencializado com a agitação ultrassônica, mas não diferente das soluções de hipoclorito de sódio. 



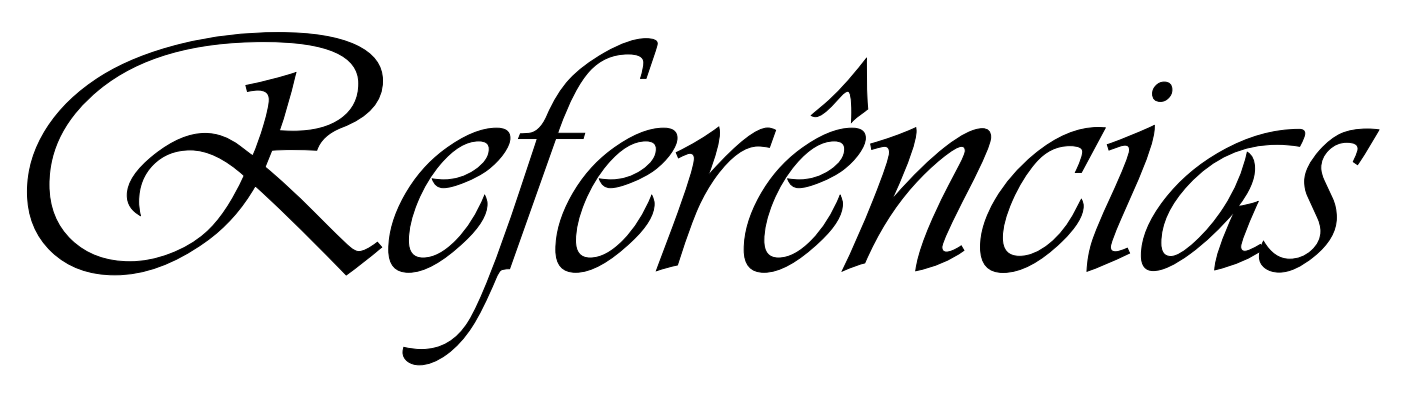





\section{REFERÊNCIAS}

1. Abou-Rass M, Piccinino MV. The effectiveness of four clinical irrigation methods on the removal of root canal debris. Oral Surg Oral Med Oral Pathol. 1982;54(3):323-8.

2. Alves FR, Almeida BM, Neves MA, Moreno JO, Rocas IN, Siqueira JF, Jr. Disinfecting oval-shaped root canals: effectiveness of different supplementaryapproaches. J Endod. 2011;37(4):496-501.

3. Andrade FB, Arias MP, Maliza AG, Duarte MA, Graeff MS, Amoroso-Silva PA, et al. A new improved protocol for in vitro intratubular dentinal bacterial contamination for antimicrobial endodontic tests: standardization and validation by confocal laser scanning microscopy. J Appl Oral Sci. 2015; 23(6):591-8.

4. Baker NA, Eleazer PD, Averbach RE, Seltzer S. Scanning electron microscopic study of the efficacy of various irrigating solutions. J Endod. 1975;1(4):127-35.

5. Basrani BR, Manek S, Fillery E. Using diazotization to characterize the effect of heat or sodium hypochlorite on $2.0 \%$ chlorhexidine. J Endod. 2009; 35(9):12969.

6. Basrani BR, Manek S, Sodhi RN, Fillery E, Manzur A. Interaction between sodium hypochlorite and chlorhexidine gluconate. J Endod. 2007; 33(8):966-9.

7. Bramante CM, Duque JA, Cavenago BC, Vivan RR, Bramante AS, de Andrade FB, et al. Use of a 660-nm Laser to Aid in the Healing of Necrotic Alveolar Mucosa Caused by Extruded Sodium Hypochlorite: A Case Report. J Endod. 2015; 41(11):1899-902.

8. Bremer PJ, Monk I, Butler R. Inactivation of Listeria monocytogenes/Flavobacterium spp. biofilms using chlorine: impact of substrate, $\mathrm{pH}$, time and concentration. Lett Appl Microbiol. 2002;35(4):321-5.

9. Camargo $\mathrm{CH}$, Siviero M, Camargo SE, De Oliveira SH, Carvalho CA, Valera MC. Topographical, diametral, and quantitative analysis of dentin tubules in the root canals of human and bovine teeth. J Endod.2007; 33(4): 422-6. 
10. Cameron JA. The effect of ultrasonic endodontics on the temperature of the root canal wall. J Endod. 1988;14(11):554-9.

11. Carbajal Mejia JB. Antimicrobial effects of calcium hydroxide, chlorhexidine, and propolis on Enterococcus faecalis and Candida albicans. J Investig Clin Dent. 2013.

12. Chávez de Paz LE, Bergenholtz G, Svensäter G. The effects of antimicrobials on endodontic biofilm bacteria. J Endod. 2010; 36(1):70-7.

13. Chivatxaranukul P, Dashper SG, Messer HH. Dentinal tubule invasion and adherence by Enterococcus faecalis. Int Endod J. 2008;41(10):873-82.

14. Chhabra RS, Huff JE, Haseman JK, Elwell MR, Peters AC. Carcinogenicity of pchloroaniline in rats and mice. Food Chem Toxicol. 1991;29(2):119-24.

15. de Almeida AP, Souza MA, Miyagaki DC, Dal Bello Y, Cecchin D, Farina AP. Comparative evaluation of calcium hypochlorite and sodium hypochlorite associated with passive ultrasonic irrigation on antimicrobial activity of a root canal system infected with Enterococcus faecalis: an in vitro study. J Endod. 2014; 40(12):1953-7.

16. del Carpio-Perochena A, Bramante CM, de Andrade FB, Maliza AG, Cavenago BC, Marciano MA, et al. Antibacterial and dissolution ability of sodium hypochlorite in different $\mathrm{pHs}$ on multi-species biofilms. Clin Oral Investig. 2015;19(8):2067-73.

17. Estrela C, Estrela CR, Barbin EL, Spanó JC, Marchesan MA, Pécora JD. Mechanism of action of sodium hypochlorite. Braz Dent J. 2002;13(2):113-7.

18. Evans M, Davies JK, Sundqvist G, Figdor D. Mechanisms involved in the resistance of Enterococcus faecalis to calcium hydroxide. Int Endod $\mathrm{J}$. 2002;35(3):221-8.

19. Guerreiro-Tanomaru JM, Morgental RD, Flumignan DL, Gasparini F, Oliveira JE, Tanomaru-Filho M. Evaluation of $\mathrm{pH}$, available chlorine content, and antibacterial activity of endodontic irrigants and their combinations against Enterococcus faecalis. Oral Surg Oral Med Oral Pathol Oral Radiol Endod. 2011;112(1):132-5.

20. Haapasalo M, Orstavik D. In vitro infection and disinfection of dentinal tubules. J Dent Res. 1987;66(8):1375-9. 
21. Harrison AJ, Chivatxaranukul $\mathrm{P}$, Parashos $\mathrm{P}$, Messer $\mathrm{HH}$. The effect of ultrasonically activated irrigation on reduction of Enterococcus faecalis in experimentally infected root canals. Int Endod J. 2010;43(11):968-77.

22. Heard DD, Ashworth RW. The colloidal properties of chlorhexidine and its interaction with some macromolecules. J Pharm Pharmacol. 1968;20(7):505-12.

23. Klyn SL, Kirkpatrick TC, Rutledge RE. In vitro comparisons of debris removal of the EndoActivator system, the $\mathrm{F}$ file, ultrasonic irrigation, and $\mathrm{NaOCl}$ irrigation alone after hand-rotary instrumentation in human mandibular molars. J Endod. 2010;36(8):1367-71.

24. Kuroiwa K, Nakayama H, Kuwahara T, Tamagawa K, Hattori K, Murakami K, et al. Augmenting effect of acetic acid for acidification on bactericidal activity of hypochlorite solution. Lett Appl Microbiol. 2003;36(1):46-9.

25. Lee SJ, Wu MK, Wesselink PR. The effectiveness of syringe irrigation and ultrasonics to remove debris from simulated irregularities within prepared root canal walls. Int Endod J. 2004;37(10):672-8.

26. Lopes HP, Siqueira Jr. JF. Endodontia Biológica e técnica. 3ed:Guanabara Koogan; 2010.

27. Love RM. Enterococcus faecalis--a mechanism for its role in endodontic failure. Int Endod J. 2001;34(5):399-405.

28. Ma J, Wang Z, Shen Y, Haapasalo M. A new noninvasive model to study the effectiveness of dentin disinfection by using confocal laser scanning microscopy. J Endod. 2011;37(10):1380-5.

29. Maliza AGA. Desinfecção intratubular de dentes bovinos por soluções de hipoclorito de sódio acidificadas [Dissertação de Mestrado]. Bauru: Faculdade de Odontologiade Bauru - Universidade de São Paulo; 2013.

30. Mercade M, Duran-Sindreu F, Kuttler S, Roig M, Durany N. Antimicrobial efficacy of $4.2 \%$ sodium hypochlorite adjusted to $\mathrm{pH} 12,7.5$, and 6.5 in infected human root canals. Oral Surg Oral Med Oral Pathol Oral Radiol Endod. 2009;107(2):295-8.

31. Mozo S, Llena C, Chieffi N, Forner L, Ferrari M. Effectiveness of passive ultrasonic irrigation in improving elimination of smear layer and opening dentinal tubules. J Clin Exp Dent. 2014;6:47-52. 
32. Naenni N, Thoma K, Zehnder M. Soft tissue dissolution capacity of currently used and potential endodontic irrigants. J Endod. 2004;30(11):785-7.

33. Nakajo K, Komori R, Ishikawa S, Ueno T, Suzuki Y, Iwami Y, et al. Resistance to acidic and alkaline environments in the endodontic pathogen Enterococcus faecalis. Oral Microbiol Immunol. 2006;21(5):283-8.

34. Ordinola- Zapata. [Dissertação de Mestrado]. Bauru: Faculdade de Odontologiade Bauru - Universidade de São Paulo;2009.

35. Peciuliene V, Reynaud AH, Balciuniene I, Haapasalo M. Isolation of yeasts and enteric bacteria in root-filled teeth with chronic apical periodontitis. Int Endod J. 2001;34(6):429-34.

36. Penas PP, Mayer MP, Gomes BP, Endo M, Pignatari AC, Bauab KC, Pinheiro ET. Analysis of genetic lineages and their correlation with virulence genes in Enterococcus faecalis clinical isolates from root canal and systemic infections. $J$ Endod. 2013 Jul;39(7):858-64.

37. Pinheiro ET, Gomes BP, Ferraz CC, Sousa EL, Teixeira FB, Souza-Filho FJ. Microorganisms from canals of root-filled teeth with periapical lesions. Int Endod J. $2003 ; 36(1): 1-11$.

38. Ricucci D, Siqueira JF Jr, Bate AL, Pitt Ford TR. Histologic investigation of root canal-treated teeth with apical periodontitis: a retrospective study from twentyfour patients. J Endod. 2009;35(4):493-502.

39. Rodig T, Sedghi M, Konietschke F, Lange K, Ziebolz D, Hulsmann M. Efficacy of syringe irrigation, RinsEndo and passive ultrasonic irrigation in removing debris from irregularities in root canals with different apical sizes. Int Endod J. 2010;43(7):581-9.

40. Siqueira JF Jr. Aetiology of root canal treatment failure: why well-treated teeth can fail. Int Endod J 2001;34:1-10.

41. Siqueira JF Jr, Batista MM, Fraga RC, de Uzeda M. Antibacterial effects of endodontic irrigants on black-pigmented gram-negative anaerobes and facultative bacteria. J Endod. 1998;24(6):414-6. 
42. Siqueira JF Jr, De Uzeda M, Fonseca ME. A scanning electron microscopic evaluation of in vitro dentinal tubules penetration by selected anaerobic bacteria. J Endod. 1996;22(6):308-10.

43. Siqueira JF Jr, Machado AG, Silveira RM, Lopes HP, de Uzeda M. Evaluation of the effectiveness of sodium hypochlorite used with three irrigation methods in the elimination of Enterococcus faecalis from the root canal, in vitro. Int Endod J. 1997;30(4):279-82.

44. Stuart $\mathrm{CH}$, Schwartz SA, Beeson TJ, Owatz CB. Enterococcus faecalis: its rolein root canal treatment failure and current concepts in retreatment. $J$ Endod.2006;32(2):93-8.

45. van der Sluis LW, Vogels MP, Verhaagen B, Macedo R, Wesselink PR. Study on the influence of refreshment/activation cycles and irrigants on mechanical cleaning efficiency during ultrasonic activation of the irrigant. $J$ Endod. 2010;36(4):737-40.

46. van der Sluis LW, Versluis M, Wu MK, Wesselink PR. Passive ultrasonic irrigation of the root canal: a review of the literature. Int Endod $\mathrm{J}$. 2007;40(6):415-26.

47. Vera J, Siqueira JF Jr, Ricucci D, Loghin S, Fernández N, Flores B, et al. Oneversus two-visit endodontic treatment of teeth with apical periodontitis: a histobacteriologic study. J Endod 2012;38:1040-52.

48. White RR, Hays GL, Janer LR. Residual antimicrobial activity after canal irrigation with chlorhexidine. J Endod. 1997;23(4):229-31.

49. Wu MK, Wesselink PR. Efficacy of three techniques in cleaning the apical portion of curved root canals. Oral Surg Oral Med Oral Pathol Oral Radiol Endod 1995; 79:492-6.

50. Zehnder M. Root canal irrigants. J Endod. 2006;32(5):389-98. 



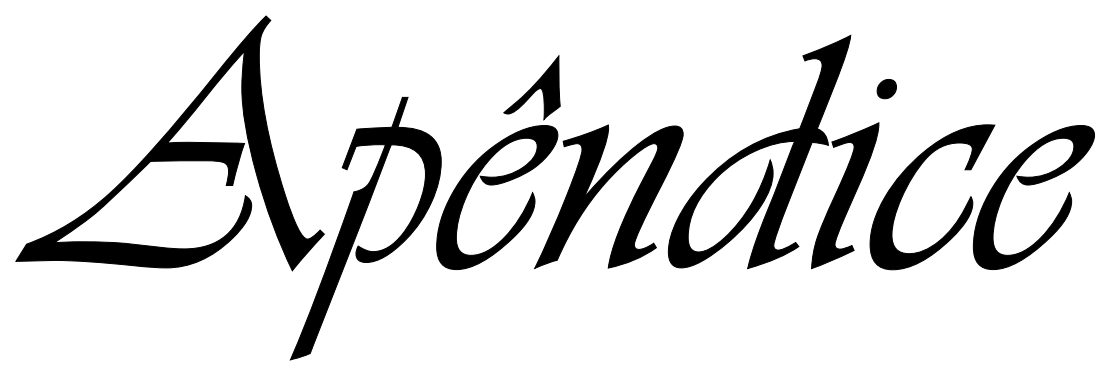



Tabela 1: Grupos que apresentaram diferenças estatísticas significativas na região superficial após aplicação dos testes estatísticos $(p<0.05)$.

\begin{tabular}{cc}
\hline Grupos & Mediana \\
\hline CLX US & $0,03(0,00-1,15)^{\mathrm{c}}$ \\
$\mathrm{NaOCl} 1 \% \mathrm{pH} 5$ & $0,61(0,13-7,63)^{\mathrm{bc}}$ \\
$\mathrm{NaOCl} 2,5 \% \mathrm{pH} 5$ & $0,66(0,00-4,54)^{\mathrm{ce}}$ \\
$\mathrm{NaOCl} 2,5 \% \mathrm{pH} 5$ US & $0,69(0,04-1,59)^{\mathrm{ce}}$ \\
$\mathrm{NaOCl} 1 \% \mathrm{pH} 5$ US & $0,99(0,02-1,97)^{\mathrm{bcd}}$ \\
$\mathrm{NaOCl} 1 \% \mathrm{pH} 10$ US & $2,73(0,50-15,46)^{\mathrm{bde}}$ \\
$\mathrm{NaOCl} 2,5 \% \mathrm{pH} 10$ & $3,33(0,38-23,51)^{\mathrm{bde}}$ \\
$\mathrm{NaOCl} 2,5 \mathrm{pH} 10$ US & $3,87(0,54-13,18)^{\mathrm{abd}}$ \\
$\mathrm{NaOCl} 1 \% \mathrm{pH} 10$ & $4,22(0,37-23,67)^{\mathrm{ad}}$ \\
CLX & $4,69(0,27-27,85)^{\mathrm{ab}}$ \\
CONTROLE POSITIVO & $74,34(29,28-94,61)^{\mathrm{a}}$ \\
\hline
\end{tabular}

* Letras diferentes representam diferença estatística significante $(p<0,05)$

Tabela 2: Grupos que apresentaram diferenças estatísticas significativas na região profunda após aplicação dos testes estatísticos $(p<0.05)$.

\begin{tabular}{cc}
\hline Grupos & Mediana \\
\hline CLXUS & $0,45(0,00-9,17)^{\mathrm{b}}$ \\
$\mathrm{NaOCl} 2,5 \%$ pH 5 US & $0,77(0,00-7,37)^{\mathrm{b}}$ \\
$\mathrm{NaOCl} 2,5 \%$ pH 5 & $0,84(0,00-2,93)^{\mathrm{b}}$ \\
$\mathrm{NaOCl} 1 \%$ pH 5 US & $1,38(0,02-4,92)^{\mathrm{b}}$ \\
$\mathrm{NaOCl} 1 \%$ pH 5 & $1,85(0,13-24,83)^{\mathrm{b}}$ \\
$\mathrm{NaOCl} 1 \%$ pH 10 US & $2,12(0,50-16,98)^{\mathrm{bc}}$ \\
$\mathrm{CLX}$ & $4,53(0,09-27,85)^{\mathrm{bc}}$ \\
$\mathrm{NaOCl} 2,5 \%$ pH 10 & $5,29(0,38-23,51)^{\mathrm{bc}}$ \\
$\mathrm{NaOCl} 2,5 \mathrm{pH} 10$ US & $5,39(0,10-13,18)^{\mathrm{c}}$ \\
$\mathrm{NaOCl} 1 \%$ pH 10 & $6,61(1,30-23,90)^{\mathrm{ac}}$ \\
$\mathrm{CONTROLE} \mathrm{POSITIVO}$ & $73,96(41,63-94,61)^{\mathrm{a}}$ \\
\hline
\end{tabular}

* Letras diferentes representam diferença estatística significante $(p<0,05)$ 
Tabela 3: Grupos que apresentaram diferenças estatísticas significativas no terço cervical após aplicação dos testes estatísticos $(p<0.05)$.

\begin{tabular}{cc}
\hline Grupos & Mediana \\
\hline CLXUS & $0,03(0,00-1,15)^{\mathrm{c}}$ \\
$\mathrm{NaOCl} 1 \% \mathrm{pH} 5$ & $0,61(0,13-7,63)^{\mathrm{bc}}$ \\
$\mathrm{NaOCl} 2,5 \% \mathrm{pH} 5$ & $0,66(0,00-4,54)^{\mathrm{ce}}$ \\
$\mathrm{NaOCl} 2,5 \% \mathrm{pH} 5$ US & $0,69(0,04-1,59)^{\mathrm{ce}}$ \\
$\mathrm{NaOCl} 1 \% \mathrm{pH} 5$ US & $0,99(0,02-1,97)^{\mathrm{bcd}}$ \\
$\mathrm{NaOCl} 1 \% \mathrm{pH} 10$ US & $2,73(0,50-15,46)^{\mathrm{bde}}$ \\
$\mathrm{NaOCl} 2,5 \% \mathrm{pH} 10$ & $3,33(0,38-23,51)^{\mathrm{bde}}$ \\
$\mathrm{NaOCl} 2,5 \mathrm{pH} 10$ US & $3,87(0,54-13,18)^{\mathrm{abd}}$ \\
$\mathrm{NaOCl} 1 \% \mathrm{pH} 10$ & $4,22(0,37-23,67)^{\mathrm{ad}}$ \\
$\mathrm{CLX}$ & $4,69(0,27-27,85)^{\mathrm{ab}}$ \\
$\mathrm{CONTROLE} \mathrm{POSITIVO}$ & $74,34(29,28-94,61)^{\mathrm{a}}$ \\
\hline
\end{tabular}

* Letras diferentes representam diferença estatística significante $(p<0,05)$

Tabela 4: Grupos que apresentaram diferenças estatísticas significativas no terço cervical após aplicação dos testes estatísticos $(p<0.05)$.

\begin{tabular}{cc}
\hline Grupos & Mediana \\
\hline $\mathrm{CLXUS}$ & $0,40(0,00-9,17)^{\mathrm{b}}$ \\
$\mathrm{NaOCl} 2,5 \%$ pH 5 US & $0,68(0,00-7,37)^{\mathrm{bc}}$ \\
$\mathrm{NaOCl} 1 \%$ pH 5 US & $0,79(0,06-4,92)^{\mathrm{bc}}$ \\
$\mathrm{NaOCl} 2,5 \% \mathrm{pH} 5$ & $0,84(0,00-3,58)^{\mathrm{b}}$ \\
$\mathrm{NaOCl} 1 \% \mathrm{pH} 5$ & $0,91(0,10-24,83)^{\mathrm{bc}}$ \\
$\mathrm{NaOCl} 1 \% \mathrm{pH} 10 \mathrm{US}$ & $1,85(0,24-16,98)^{\mathrm{bc}}$ \\
$\mathrm{CLX}$ & $2,77(0,02-23,97)^{\mathrm{bc}}$ \\
$\mathrm{NaOCl} 2,5 \% \mathrm{pH} 10 \mathrm{US}$ & $3,73(0,10-11,79)^{\mathrm{bc}}$ \\
$\mathrm{NaOCl} 2,5 \%$ pH10 & $5,54(0,36-19,74)^{\mathrm{bc}}$ \\
$\mathrm{NaOCl} 1 \% \mathrm{pH} 10$ & $5,74(1,00-23,90)^{\mathrm{ac}}$ \\
$\mathrm{CONTROLE} \mathrm{POSITIVO}$ & $68,05(41,63-92,44)^{\mathrm{a}}$ \\
\hline
\end{tabular}

* Letras diferentes representam diferença estatística significante $(p<0,05)$ 


\section{Bactérias viáveis}

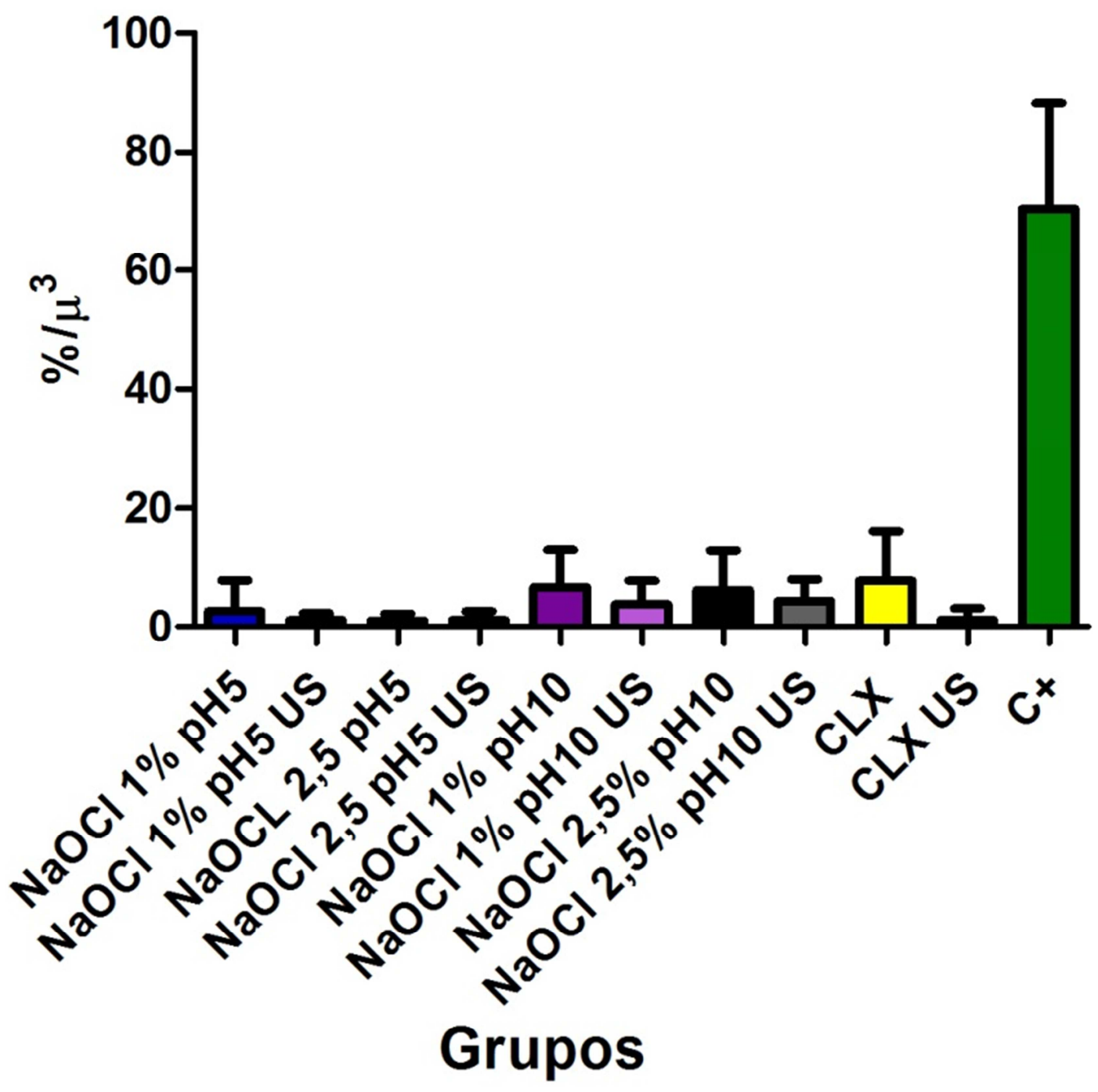

Figura 1: Gráfico representativo da porcentagem das bactérias viáveis após o tratamento com as soluções irrigadoras. Análise no MCVL. 


\section{Terço Cervical}

\section{Bactérias viáveis}

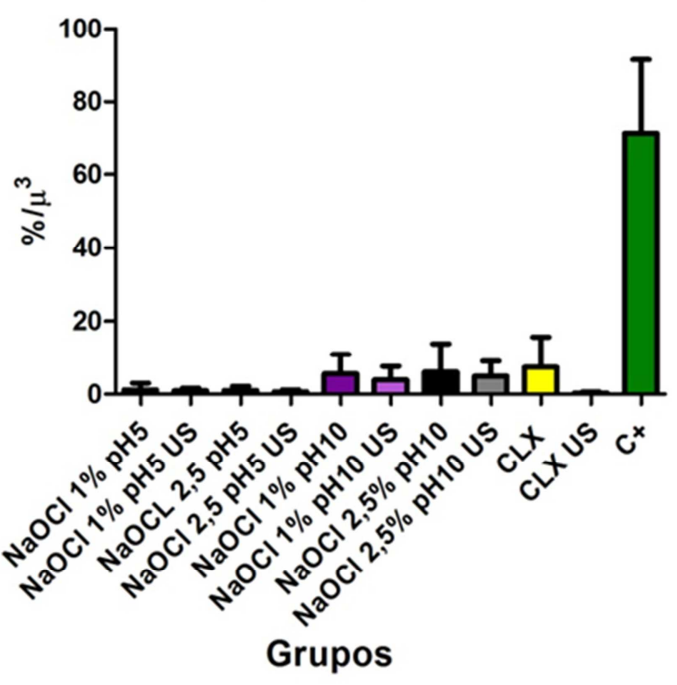

Região Superficial

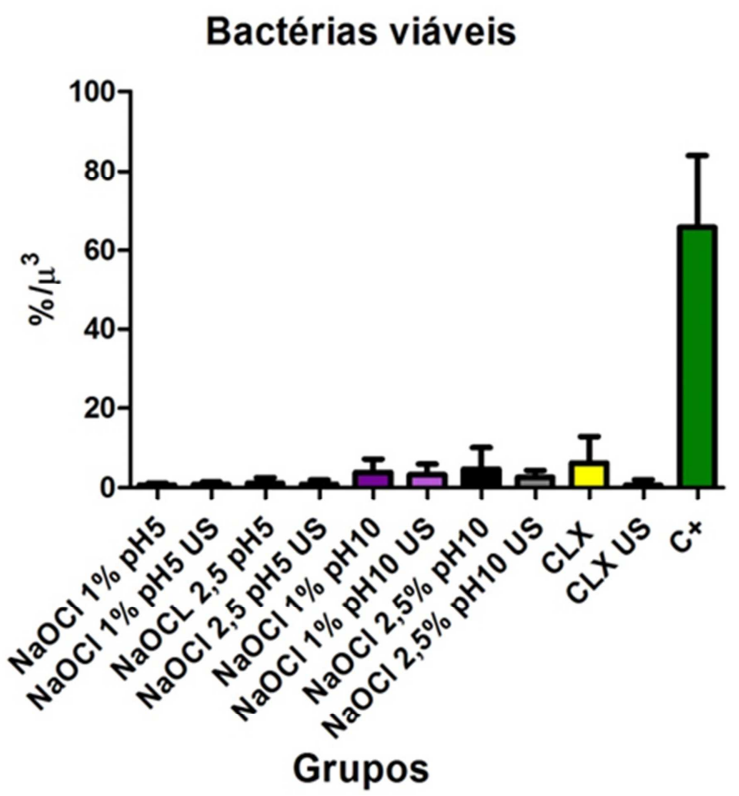

\section{Terço médio}

Bactérias viáveis

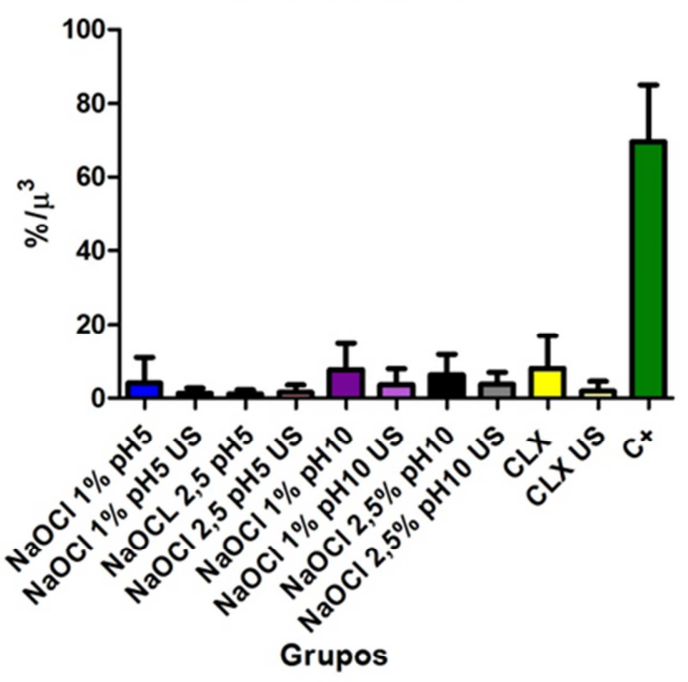

Região Profunda

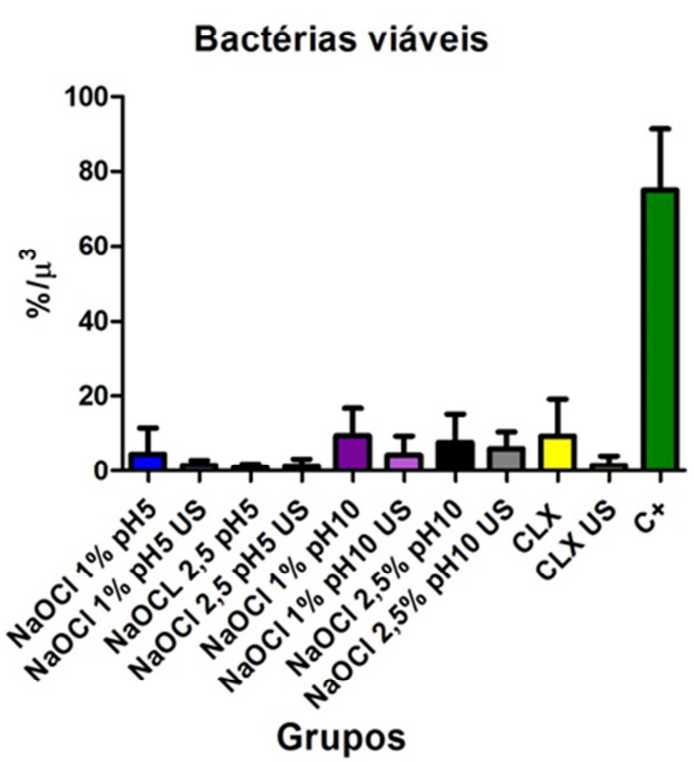

Figura 2: Gráficos representativos das porcentagens de bactérias viáveis nos terços cervical e médio e nas regiões superficial e profunda em relação a luz do canal, após o tratamento com as soluções irrigadoras. Análise no MCVL. 